\title{
Ueber Hydrobenzoësäuren;
}

von Ossian Aschan.

(Eingelaufen am 24. Juni 1892.)

Den sog. hydroaromatischen Substanzen wurde eine Zeit hindurch eine bescheidene Stellung unter den organischen Verbindungen angewiesen. Die ersten Repräsentanten dieser Classe, unter den Wreden's Hexahydrobenzole, Bae yer's Hexahydromellithsäure, das ebenfalls schon längst bekannte Benzolhexachlorid resp. -bromid etc. genannt werden können, sind gewissermassen als eine Art Molekularverbindungen aufgefasst und demnach zu den Benzolkörpern gerechnet worden. Einige in vielen heutigen Lehr- und Handbüchern noch vorkommende Formeln, wie z. B. $\mathrm{C}_{6} \mathrm{H}_{6} \cdot \mathrm{H}_{6}$ für Hexahydrobenzol, deuten auf diese Anschauungsweise hin. Erst in der allerneuesten Zeit haben diese Substanzen das Interesse der Chemiker in höherem Maasse erweckt. Einerseits sind ihre Beziehungen zu einigen in der Natur vorkommenden grösseren Körperclassen, wie den Terpenen und Campherarten, deren genauere Kenntniss wir den grossen Arbeiten von Wallach und Brühl verdanken, ferner den in dem Erdöl aus verschiedenen Gegenden auftretenden Naphtenen, welche besonders von Markownik ow und seinen Schülern studirt worden sind, deutlicher hervorgetreten. Andererseits haben die interessanten und umfassenden Untersuchungen v. Baeyer's äber die Constitution des Benzols die Aufmerksamkeit auf dieselben gelenkt. Besonders haben v, Baeyer's Arbeiten dargethan, dass die Hydrobenzole keine aromatischen Substanzen mehr sind. Sobald zwei Wasserstoffatome an dem Benzolkern angelagert worden, wird die eigenthümliche Bindungsart aufgehoben, welche demselben den sog. aromatischen Charakter verleiht. Der Dihydrobenzolkörper hat die Eigenschaften einer ungesättigten aliphatischen Verbindung angenommen, welche auch bei weiterer Addition zweier Wasserstoffatome beibehalten werden. Schliesslich gleichen die Hexa- 
hydroderivate der Benzolverbindungen ihrem chemischen Verhalten nach fast vollständig den gesättigten Fettkörpern. Mit einem Worte, die hydroaromatischen Substanzen gehören mehr der aliphatischen als der aromatischen Reihe an; in Bezug darauf hat ihnen Bamberger den glücklich gewählten Namen „alicyllisch" beigelegt.

Die vorliegende Untersuchung ${ }^{1}$ ) über etliche aus der einfachsten aromatischen Carbonsäure erhaltenen Hydroverbindungen enthält einige Beobachtungen, welche zur weiteren Bestätigung der von A. v. Ba ey er festgestellten Thatsachen dienen können. Ursprünglich bezweckte die Arbeit nur eine Darstellung der Hexahydrobenzoësäure, um sie mit einer aus dem Erdöl von Baku isolirten Säure derselben Zusammensetzung, der Hexanaphtencarbonsäure $\left.{ }^{2}\right) \mathrm{C}_{7} \mathrm{H}_{12} \mathrm{O}_{2}$, zu vergleichen; dieser Theil der Untersuchung hat die Nichtidentität der beiden Säuren festgestellt. Da es sich während dieser Arbeit herausstellte, dass ausser der völlig hydrirten Verbindung einige ungesättigte Hydrobenzoësäuren leicht zu erhalten waren, wurden auch diese näher untersucht. Die Untersuchung ist im chemischen Laboratorium der königl. Akademie der Wissenschaften in München begonnen und im hiesigen Universitätslaboratorium fortgesetzt worden.

Folgende Literaturangaben sind der Beschreibung der experimentellen Ergebnisse vorauszuschicken.

Kolbe hatte im Jahre 1861 beobachtet, dass Benzoësäure in saurer Lösung durch Natriumamalgam rasch reducirt wird; von der Einwirkung des Amalgams in alkalischer Lösung erwähnt er kurz, dass sie anfangs rascher verläuft, aber träger wird, sobald sich ein Ueberschuss an Alkali in der Lösung anhäuft. Die Untersuchung wurde von Herrmann ${ }^{4}$ ) weiter-

1) Kürzere Notizen über diesen Gegenstand sind in Ber. d. deutsch. chem. Ges. 24, 1864 u. 2617 zu finden.

2) Ber. d. dentsch. chem. Ges. 23. 867 .

3) Diese Annalen 118, 122.

4) Diese Annalen $138,75$. 
geführt, der die Producte der Reduction oingehender studirte. Er liess Natriumamalgam unter Erwärmen auf eine concentrirte, wässrige Lösung von Benzoësäure einwirken, die er durch zeitweiliges Einleiten von Chlorwasserstoff stets sauer erhielt. Hierbei wurde der grösste Theil des Materials zu Benzylalkohol und einem krystallinischen, bei $116^{0}$ schmelzenden Körper von der Zusammensetzung $\mathrm{C}_{14} \mathrm{H}_{14} \mathrm{O}_{\mathrm{z}}$ verwandelt. Gleichzeitig entstand eine baldrianähnlich riechende, ölige Säure, von Herrmann Benzoleïnsäure genannt, deren Zusammensetzung $\mathrm{C}_{7} \mathrm{H}_{10} \mathrm{O}_{2}$ einer Tetrabydrobenzoësäure durch die Analyse des Methylesters festgestellt wurde. Ihre Salze wurden beim Umkrystallisiren leicht oxydirt. Eine ähnliche, möglicherweise identische Säure hat Robert Otto5) etwas später erhalten, als er Hippursäure mit Natriumamalgam reducirte und das Reactionsproduct mit Kalilauge verseifte. Bei der Reduction von Benzoylglycolsäure hat 0 tt $0^{6}$ ) ebenfalls eine gleichartige Substanz aufgefunden. In der erstgenannten Abhandlung ${ }^{7}$ ) beschreibt derselbe Autor anch eine Dihydrobenzoësäurc, die beim Umkrystallisiren des Calciumsalzes der Benzoleïnsäure entstehen soll, einen unangenehmen Geruch besitzt und durch den Luftsauerstoff zu Benzoësäure oxydirt wird. Der Schmelzpunkt, der unscharf bei $90-110^{\circ}$ liegt, und ihre sonstigen Eigenschaften deuten indess mehr auf ein Gemenge aus Benzoësäure und Tetrahydrobenzoësäure.

Die neuere chemische Literatur enthält folgende Angaben über die Hydrobenzoësåuren. Während seiner Arbeiten über die Hydrirungsproducte der Terephtalsäure hat v. Baeyer ${ }^{8}$ ) wahrscheinlich zwei dieser Säuren unter den Händen gehabt. Eine Dihydrobenzoësäure haben weiter Einhorn und Eichengrün ${ }^{9}$ ) aus dem Dihydrobenzaldehyd, den sic aus

5) Diesc Annalen 134, 303.

G) Diese Annalen 145, 350 .

7) Diese Annalen 134, 319.

8) Diese Annalen 245, 151 u. 166.

9) Ber. d. deutsch. chem. Ges. 23, 2870.

Annalen der Chemie 271. Bd. 
Anhydroecgonin durch Kochen mit Sodalösung erhielten, mittelst Silberoxyd dargestellt; sie ist eine luftbeständige, wohlcharakterisirte Verbindung, welche bei $94-95^{\circ}$ schmilat. In der jüngsten Zeit ist eine isomere Dihydrosäure von $\mathrm{H}$ u tch in $\mathrm{s} \mathrm{on}^{10}$ ) durch Reduction von Benzamid in alkalischer Lösung und Verseifen des dabei gebildeten Dihydrobenzamids erhalten. Sie wird als eine bei $53-54^{\circ}$ schmelzende Krystallmasse, die ziemlich unbeständig ist und durch Oxydation an der Luft in Benzoësäure übergeht, beschrieben. Schliesslich ist zu erwähnen, dass Markownikow eine Säure von der Zusammensetzung $\mathrm{C}_{7} \mathrm{H}_{12} \mathrm{O}_{2}$ beschrieben hat ${ }^{11}$ ), erhalten durch Kochen von Benzoësäure mit Natrium in amylalkoholischer Lösung, welche allem Anscheine nach mit der später zu beschreibenden Hexahydrobenzoësäure identisch ist.

\section{Die Hydrirung der Benzoësäure in alkalischer Lösung}

unter gleichzeitigem Einleiten von Kohlendioxyd, wobei die $\boldsymbol{A}^{2}$ Tetrahydrobenzoësäure als Hauptproduct entsteht, habe ich schon in einer früher publicirten Notiz ${ }^{12}$ ) beschrieben. Bei spätereren Darstellungen dieser Säure hat es sich als vortheilhaft herausgestellt, in möglichst concentrirten Lösungen zu arbeiten. Man spart sich deshalb viel Zeit, wenn man, nachdem ungefähr die Hälfte des Amalgams eingeführt und verbraucht worden, die entstandenen Producte abscheidet, weil die Lösung sonst mit Soda übersättigt wird und ziemlich viel Wasser hinzugefügt werden muss, um das Salz gelöst zu halten. Zu dem Ende fügt man zu der warmen Flüssigkeit Schwefelsäure bis zu schwach saurer Reaction, lässt einige Stunden zur Abscheidung der Kieselsäure stehen, säuert dann mit Schwefelsäure stark an und extrahirt zweimal mit Aether. Die Aetherlösung wird mit Wasser gewaschen, im Wasserbade destillirt,

10) Inaug.-Diss., Würzburg 1892, S. 30.

11) Ber. d. deutseh. chem. Ges. 25, 370. Vgl. auch ebendas. 25, 886.

12) Ber. d. deutsch. chem. Ges. 24, 1865. 
der ölige Rückstand, welcher wegen des Gehaltes an unangegriffener Benzoësäure beim Erkalten oft butterartige Consistenz annimmt, in möglichst wenig reiner Sodalösung gelöst und die nunmehr concentrirtere Lösung weiter mit dem Amalgam behandelt. Nachdem eine Probe der Flüssigkeit nach dem Ansäuern eine ölige Säure abscheidet, die auch nach mehrstündigem Stehen völlig flússig bleibt, ist die Einwirkung als beendet zu betrachten. Das Product wird nunmehr in der früher beschriebenen Weise isolirt.

Ich habe mehrmals versucht, die verschiedenen Phasen der Reduction der Benzoësäure zu verfolgen und speciell waren meine Bemühnngen darauf gerichtet, eine etwa intermediär gebildete Dihydrosäure zu isoliren, aber vergebens.

Die aus mebreren Darstellungen herrührenden neutralen Nebenproducte habe ich vereinigt untersucht. Nach dem Abdestilliren des Extractions-Aethers bleibt ein Oel zurück, welches kaum noch ammoniakalische Silberlösung reducirt, also Aldehyde nur spurenweise enthält. Bei der Destillation steigt die Temperatur sehr rasch bis auf $200^{\circ}$, und es geht bei 202 bis $203^{0}$ Benzylalkohol uber. Bei nochmaligem Rectificiren destillirt es ganz constant bei $202^{0}$ (uncorr.). Um den krystallinischen Rückstand, der nach dem Abdestilliren des Benzylalkohols im Kolben zurückbleibt, zu reinigen, wurde or auf porösen Platten vom Oel befreit und aus verdünntem Alkohol dreimal umkrystallisirt. Der Körper scheidet sich in grossen, perlmutterglänzenden Blättern aus, schmilzt bei $134^{\circ}$ und zeigt die Eigenschaften des gewöhnlichen Hydrobenzoïns. $\mathrm{Zu}$ bemerken ist, dass Herrmann ${ }^{13}$ ) als Nebenproduct bei der Darstellung seinor Benzolë̈nsäure eine Verbindung von der Zusammensetzung dos Hydrobenzoïs erhalten hat, welche indessen den Schmelzpunkt $116^{\circ}$ zeigt, und somit wohl mit dem isomeren Isohydrobenzoin identisch ist. Was die Bildung der Hydrobenzoïne betrifft, so lässt sie sich einfach auf die Ein-

13) Dieso Annalen 132. 
wirkung des nascenten Wasserstoffs auf den als erstes Reductionsproduct des Benzoësäurecarboxyls auftretenden Benzaldehyd zuräckführen.

$\boldsymbol{A}^{2}$ Tetrahydrobenzö̈süure, $\mathrm{C}_{7} \mathrm{H}_{10} \mathrm{O}_{2}$.

Die rohe Säure, welche nach der Reduction der Benzoësäure aus der alkalischen Lösung abgeschieden wird, besitzt eine gelbliche Farbe und ist, weil sie hartnäckig Wasser und Aether zurückhält, keineswegs rein. Ausserdem enthält sie oft Spuren von Benzoësäure, deren Menge wegen ihrer leichten Oxydirbarkeit durch den Luftsauerstoff schnell zunimmt; in einer Probe, die in einem Uhrglase an der Luft steht, sieht man oft schon nach 24 Stunden Krystalle von Benzoësäure auftreten. Findet die freiwillige Oxydation in einem mit Korkstopfen verschlossenen Gefäss statt, so wird dieses gebleicht und mürbe. Die freie Säure verhält sich also ihrem Methylester analog ${ }^{14}$ ).

Die $A^{2}$ Tetrahydrobenzoësäure lässt sich destilliren, doch muss die Operation im Kohlendioxydstrome ansgeführt werden. Der Siedepunkt liegt bei $234-235^{\circ}$ (Quecksilber ganz im Dampf). Hierbei wird sie spurenweise in ein neutrales, flüssiges Product verwandelt, welches einen schwach esterartigen Geruch besitzt, in Wasser ziemlich leicht löslich ist und vermuthlich das isomere Lacton der $\gamma$-Hydroxyhexahydrobenzoësäure darstellt. Wäre diese Annahme richtig, so würde seine Entstehung einen neuen Beweis abgeben für die Aehnlichkeit der tetrahydrirten aromatischen Säuren mit den ungesättigten Säuren der Fettreihe, die nach Fittig's Untersuchungen in die isomeren $\gamma$-Lactone übergehen, wenn die doppelte Bindung in $\beta \gamma$ - resp. $\gamma \delta$-Stellung zum Carboxyl steht.

Wenn man die destillirte $A^{2}$ Tetrahydrosäure in Soda auflöst, die Lösung mit absolut reinem Aether von neutralen Producten befreit und von Neuem mit Schwefelsäure und Aether abscheidet, so kann eine reine wässrige Lösung der Säure erhalten werden. Zu dem Ende wurde sie in luftfreiem Wasser

14) Aschan, Ber. d. deutsch. chem. Ges. 24, 1865. 


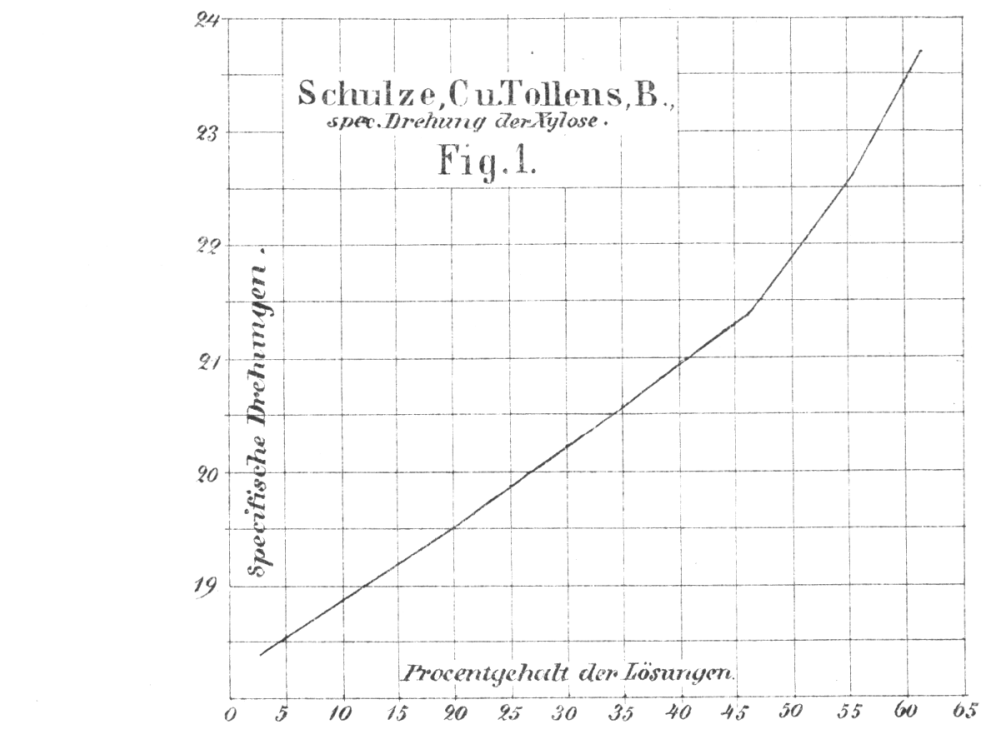

Liebig's Annalen derChemie. Bd.271.Tat.1.
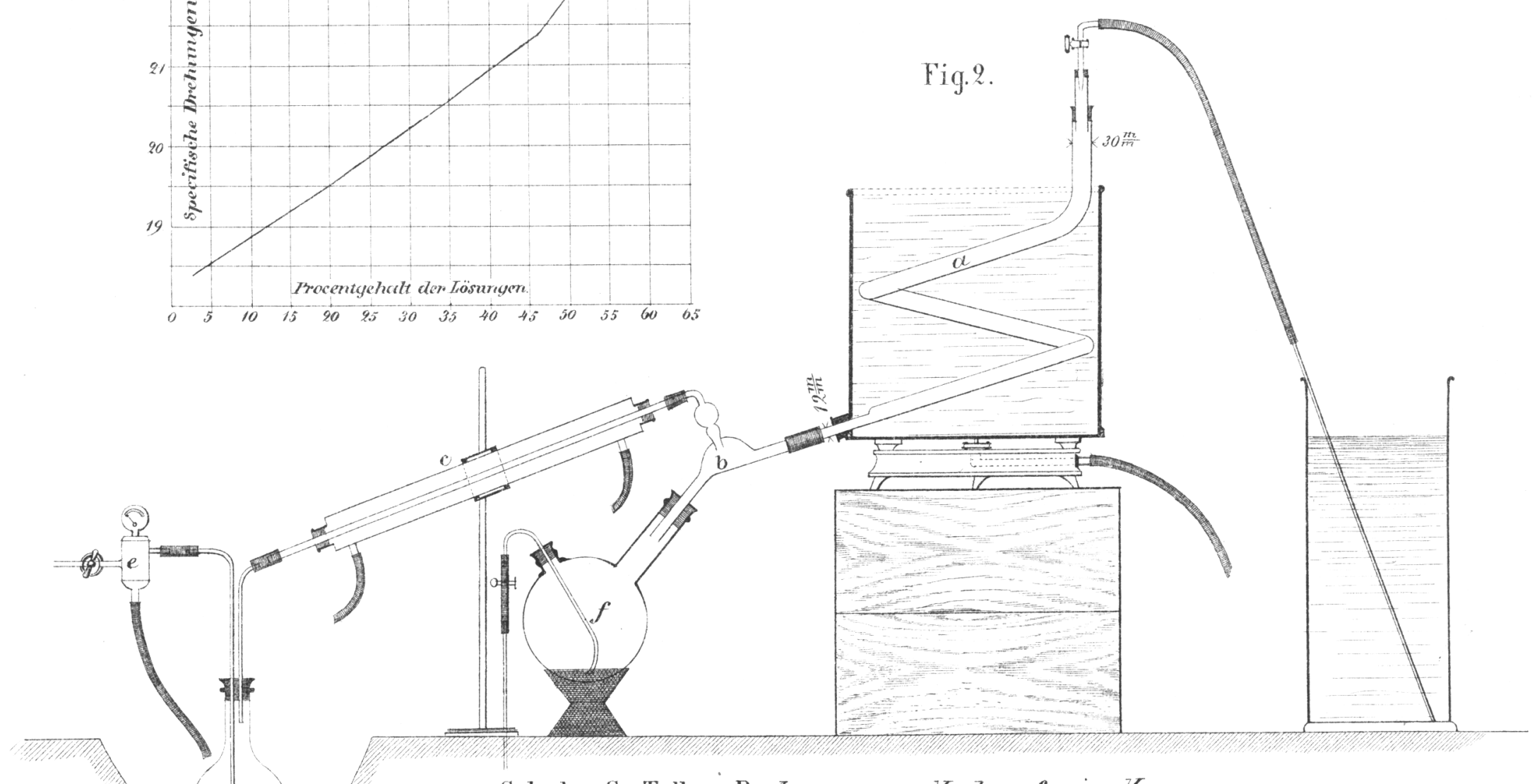

Schulze,Cu,Tollens,B. Apparat zum Verdampfen im Vacumm. 
gelöst und die mitgelösten Spuren von Aether durch Kochen entfernt. In einer derart bereiteten Lösung bestimmte Herr Magister U. Collan die Löslichkeit und das Leitungsvermögen der Säure, wofür ich ihm an dieser Stelle meinen Dank ausspreche. Derselbe erhielt folgende Zahlen:

\begin{tabular}{rrrc}
\multicolumn{4}{c}{$\mu_{\infty}=355$} \\
$v$ & $\mu$ & $100 \mathrm{~m}$ & $100 \varkappa$ \\
16 & 7,70 & 2,17 & 0,00301 \\
$\mathbf{3 2}$ & 10,96 & 3,09 & 0,00308 \\
64 & 15,37 & 4,33 & 0,00306 \\
128 & 21,15 & 5,96 & 0,00300 \\
256 & 28,91 & 8,14 & 0,00282 \\
512 & 38,66 & 10,89 & 0,00260 \\
1024 & 50,47 & 14,21 & 0,00230
\end{tabular}

$$
K=0,00305 \text {. }
$$

Löslichkeit: $100 \mathrm{cem}$ Wasser lösen bei $20^{\circ} 1,34 \mathrm{~g}$.

Die Zahlen, welche das Leitungsvermögen darstellen, nehmen bei zunehmender Verdünnung ab, was wohl auf die leichte Oxydirbarkeit der Säure zurückzufübren ist.

In folgender Weise bin ich auch zu einem ziemlich reinen Präparate gekommen. Aus dem später zu beschreibenden Dibromid vom Schmelzpunkt $166^{\circ}$, welches ganz rein war, wurden die Bromatome mit Natriumamalgam eliminirt, was sehr leicht gelingt. Die mit Aether in gewöhnlicher Weise isolirte, bromfreie Tetrahydrosäure wurde im Oelbade bis auf $150^{\circ}$ erhitzt und ein trockner Kohlendioxydstrom hindurchgeleitet, um Wasser und Aether zu entfernen. Nach dem Erkalten wurde versucht, die Säure zum Erstarren zu bringen, um dadurch eine wirksamere Reinigung $\mathrm{zu}$ erzielen, aber vergebens. Obwohl eine Probe während 30 Stunden einer Winterkälte von - 10 bis $-14^{\circ}$ ausgesetzt wurde, fand keine Krystallbildung statt. Deshalb musste die flüssige Säure analysirt werden.

$0,3356 \mathrm{~g}$ gaben $\mathrm{U}, 9099 \mathrm{CO}_{2}$ und $0,2433 \mathrm{H}_{2} \mathrm{O}$.

$\begin{array}{ccr} & \text { Berechnet für } & \text { Gefunden } \\ & \mathrm{C}_{7} \mathrm{H}_{10} \mathrm{O}_{8} & \\ \mathrm{C} & 66,6 \mathrm{~T} & 65,82 \\ \mathrm{H} & 7,93 & 8,06\end{array}$


Obwohl die gefundenen Zahlen mit den berechneten nicht ganz übereinstimmen, lassen sie doch keinen Zweifel über die Zusammensetzung der Säure, die auch durch die Analysen der Salze bestătigt wird.

Das Calciumsalz $\left(\mathrm{C}_{6} \mathrm{H}_{9} \mathrm{COO}\right)_{2} \mathrm{Ca}$ entsteht, wenn eine concentrirte ammoniakalische Lösung der Säure mit Chlorcalcium versetzt wird. Es bildet zusammengewachsene Nadeln, und ist auch in kaltem Wasser ziemlich leicht, etwas schwieriger in Alkohol löslich.

$0,4303 \mathrm{~g}$, bei $110^{\circ}$ getroeknet, gaben $0,1451 \mathrm{CaCO}_{3}$.

Berechnet für Gefunden

$\mathrm{Ca} \quad 13,79 \quad 13,49$ $\left(\mathrm{C}_{7} \mathrm{H}_{9} \mathrm{O}_{2}\right)_{2} \mathrm{Ca}$

Silbersalz, $\mathrm{C}_{6} \mathrm{H}_{9}$. C0OAg. Die Säure wurde in Ammoniak gelöst und mit Silbernitrat ausgefällt, wobei das Salz als käsiger Niederschlag erhalten wird. Fs ist in heissem Wasser etwas löslich, in kaltem unlöslich und gegen Licht sehr empfindlich; beim Trocknen über Schwefelsäure nimmt es eine schwach ziegelrothe Färbung an. Beim Erhitzen schmilzt es zu einer schwarzen Flüssigkeit. Gleich anderen Salzen dieser Säure wird es beim Kochen mit Wasser theilweise zersetzt.

$0,2115 \mathrm{~g}$ gaben $0,0978 \mathrm{Ag}$.

$\begin{array}{ccc} & \text { Berechnet für } & \text { Gefunden } \\ & \mathrm{C}_{7} \mathrm{H}_{9} \mathrm{O}_{2} \mathrm{Ag} & \\ \mathrm{Ag} & 46,36 & 46,24\end{array}$

Eine wässrige Lösung des Calciumsalzes verhält sich gegen Metallsalzlösungen in folgender Weise: Kupferacetat giebt einen flockigen, licht grünblauen, Cadmiumchlorid einen flockigen, weissen Niederschlag, Zinkacetat keine Fällung; Nickelnitrat eine krystallinische, lichtgrüne, Mercuronitrat eine krystallinische weisse, bald schwarz werdende Fällung, Mercurichlorid nur Trübung, keine Fällung; Manganchlorür, Magnesiumchlorid, Baryumchlorid geben keine Fällung. Bleiacetat fällt krystallinisch, weiss, Ferrichlorid giebt eine flockige, hautfarbige, Stannochlorid eine flockige, weisse Fällung. 
Methylester, $\mathrm{C}_{6} \mathrm{H}_{9} \cdot \mathrm{COOCH}_{3}$. Die Tetrabydrosäure geht sehr leicht in Ester über, schon beim Kochen derselben mit $10-20$ pC. Methyl- oder Aethylalkohol giebt sich die Esterification durch den starken und anhaftenden Geruch des Esters kund. Bis jetzt ist nur der Methylester in grösserer Menge dargestellt worden, und zwar kann man dies sowohl durch $\mathrm{Zu}$ gabe von concentrirter Schwefelsäure ( 2 Vol.) zur Lösung der Säure (1 Vol.) in Methylalkohol (21/2 Vol.), als auch durch Einleiten von trocknem Chlorwasserstoff in die Lösung bewirken. Wenn keine Reaction mehr merkbar ist, lässt mạn einige Stunden in der Kälte stehen, giesst in Eiswasser und schüttelt mit Aether aus. Nach dem Behandeln mit Sodalösung, Waschen und Trocknen wird der Aether abdestillirt und der Ester im Kohlendioxydstrome rectificirt. Er stellt eine klare, lichtbrechende Flüssigkeit dar, welche bei $188-189^{\circ}$ (Quecksilber ganz im Dampf) siedet und einen durchdringenden, zugleich an Benzoësäuremethylester und Fettsäureester erinnernden Geruch besitzt. Spec. Gew. $\mathrm{d}_{\mathrm{2} 0}^{20}=1,0433$.

$0,3096 \mathrm{~g}$ gaben $0,7783 \mathrm{CO}_{2}$ und $0,2280 \mathrm{H}_{\mathrm{\Omega}} \mathrm{O}$.

$\begin{array}{ccc} & \text { Bercchnet für } & \text { Gefunden } \\ & \mathrm{C}_{8} \mathrm{H}_{12} \mathrm{O}_{\mathbf{2}} & \\ \mathrm{C} & \mathbf{6 8 , 5 8} & 68,56 \\ \mathrm{H} & 8,58 & 8,18\end{array}$

Der Methylester nimmt in ätherischer Lösung leicht Brom auf, doch konnte das Product, weil es auch nach längerem Verweilen im Exsiccator bei niedriger Temperatur nicht erstarrte, nicht analysirt werden.

Beim Vermischen des Esters mit alhoholischem Kali tritt bald starke Erwärmung ein und es scheidet sich in blättrigen Krystallen ein Salz ab, das mit Säuren eine feste Säure liefert. Es wurde abfiltrirt, aus kochendem 96 procentigem Weingeist, worin es ziemlich schwer löslich ist, umkrystallisirt und mit Schwefelsäure zersetzt. Die feste Säure wurde durch Krystallisiren aus heissem Wasser gereinigt. Sie schmolz anfangs unter Wasser, löste sich aber beim Kochen völlig klar auf, dabei 
einen eigenthümlichen säuerlichen Geruch verbreitend. Aus der Lösung schieden sich beim Erkalten baumartig verzweigte, glänzende Nadeln ab, welche bei etwa $90^{\circ}$ anfingen zu schmelzen, aber erst bei $112^{0}$ vollkommen flüssig wurden. Wegen des änsseren Habitus der Krystalle und des niedrigen Schmelzpunktes und da sie auch, in Soda aufgelöst, Kaliumpermanganat reducirten, glaubte ich anfangs, dass eine Dihydrosäure vorliege. Es gelang mir auch einmal, bei weiterem Umkrystallisiren aus Wasser, eine bei $114-116^{0}$ ziemlich constant schmelzende Säure zu erhalten, welche in langen, spulenförmigen Prismen krystallisirte und demnach der Benzoësäure ganz unähnlich war. Trotzdem bestand sowohl diese Fraction, wie die früher erhaltenen, aus Mischungen von Benzoësäure und Tetrahydrobenzoësäure. Denn die Kaliumpermanganatreaction nimmt nach jedem Umkrystallisiren $a b$ und schliesslich bleibt nur reine Benzoësäure vom Schmelzpunkt $122^{0}$ zurtick. Das gleiche Resultat wurde erhalten, wenn man ausgekochtes, luftfreies Wasser zum Umkrystallisiren benutzte und die Abscheidung der verschiedenen Fractionen in Gefässen, die bis zum Propfen angefüllt waren, vornahm. Die Oxydation einer etwa vorliegenden Dihydrosäure durch den Sauerstoff der Luft war somit ausgeschlossen. Die Mutterlaugen, besonders die ersten, lieferten beim Eindampfen einen flüssigen Rückstand, der die Eigenschaften der Tetrahydrosäure aufwies.

Die von dem Kaliumsalz abfiltrirte alkoholische Lösung enthielt fast nur das Salz der Tetrahydrosäure, welche als nicht erstarrendes $\mathrm{Oel}$ in grosser Menge erhalten wurde.

Es wird somit ein Theil der Tetrahydrosäure beim Kochen ihres Methylesters mit alkoholischem Kali in Benzoësäure verwandelt. In Bezug auf diese Erfahrungen erscheint die Einheitlichkeit der von 0 tto $^{15}$ ) beschriebenen, beim Unkrystallisiren des sog. benzoleïnsauren Calciums erhaltenen Dihydrosäure, welche die Eigenschaften des oben beschriebenen Ge-

15) Diese Annalen 134, 320. 
menges gehabt $\mathrm{zu}$ haben scheint, fraglich. Dass die $\boldsymbol{A}^{2}$ Tetrahydrosäure, die mit der Benzoleïnsäure von Herrmann (siehe weiter unten) und anscheinend auch mit der otto'schen gleichgenannten Säure identisch ist, an der Luft direct zu Benzoësäure oxydirt wird, habe ich nämlich mehrmals gefunden. Diese Reaction bildet das Analogon zu der Thatsache, dass die alkalische Lösung der Benzoësäure durch Natriumamalgam ohne isolirbare $Z$ wischenproducte in Tetrahydrosäure verwandelt wird.

Das Tetrahydrobenzamid, $\mathrm{C}_{6} \mathrm{H}_{9} \cdot \mathrm{CONH}_{2}$, stellte ich in folgender Weise dar. $10 \mathrm{~g}$ ( $1 \mathrm{Mol}$ ) frisch dargestellte Tetrahydrosäure wurde unter Kühlung mit $17 \mathrm{~g}$ (1 Mol.) Phosphorpentachlorid portionenweise versetzt und die letzten Reste des Chlorids durch schwaches Erwärmen in Lösung gebracht. Das so erhaltene, aus Phosphoroxychlorid und Säurechlorid bestehende Gemenge wurde in einen Ueberschuss von sehr concentrirtem Ammoniak, welches mit Eis und Kochsalz stark abgekühlt war, unter häufigem Umschwenken eingetröpfelt. Es schied sich ein fester, weisser Körper aus, der aus kochendem Wasser umkrystallisirt wurde. Da beim Kochen sich deutlich ein Geruch nach höheren Fettsäurenitrilen bemerkbar machte, wurde die Lösung einige Zeit gekocht. Nach der Filtration schied sich der grösste Theil des Amides beim Abkühlen in zusammengewachsenen, grossen, perlmutterglänzenden Krystallblättern aus ; sie wurden in trocknem Zustande in Aether, worin sie nur mässig löslich waren, aufgenommen und bei freiwilligem Verdunsten des Lösungsmittels als grosse, quadratische Blätter oder Prismen mit rechtwinkliger Abstumpfung erhalten. Sie schmilzt bei $144^{\circ}$ und dieser Schmelzpunkt blieb auch nach nochmaligem Umkrystallisiren aus Wasser constant. Die aus Wasser erhaltenen Krystalle sind glanzloser und weniger deutlich ausgebildet.

$0,2225 \mathrm{~g}$ gaben $23,4 \mathrm{cem}$ Stickstoff von $21^{\circ}$ und $721 \mathrm{~mm}$ Druck. Berechnet für Gefunden $\mathrm{C}_{7} \mathrm{H}_{11} \mathrm{NO}$

N $\quad 11,20$ 11,34 
Das Amid entfärbt, in sodahaltigem Wasser aufgelöst, sofort Kaliumpermanganat. Dasselbe Verhalten zeigt, wie ich gefunden habe, das weiter unten zu beschreibende Amid der $A^{1}$ Tetrahydrosäure und, wie $H u t c h i n \operatorname{son}^{36}$ ) angiebt, auch das von ihm dargestellte Dihydrobenzamid.

Das $A^{2}$ Tetrahydrobenzamid wurde in etwas grösserer Menge dargestellt, um Aufschluss über die Einheitlichkeit der aus Benzoësäure direct entstandenen rohen Säure zu erhalten. Die Möglichkeit war nämlich nicht ausgeschlossen, dass hierbei mehr als eine Tetrahydrosäure entstehe; in diesem Falle müssten die isomeren Amide in der wässrigen resp. ätherischen Mutterlauge zu finden sein. Jene wurde mit Aether ausgeschütteit und die Lösung mit der ätherischen Mutterlange vereinigt. Nach Verdunsten des Aethers liess ich den festen Rückstand, um den schwachen noch bemerklichen Nitrilgeruch zu beseitigen, einen Tag an der Luft liegen; nachher wurde er aus heissem Wasser umkrystallisirt. Nach dem Erkalten schied sich eine Substanz in zusammengewachsenen, schönen Aggregaten aus, von den Krystallformen und dem Schmelzpunkt $144^{\circ}$ des oben beschriebenen $A^{2}$ Tetrahydrobenzamids. Die abfiltrirte Mutterlauge lieferte bcim Verdampfen an der Luft noch einige Krystallblätter derselben Form. Es geht hieraus hervor, dass die rohe, aus Benzoêsäure direct erhaltene Säure nur die oben beschriebene $\mathcal{A}^{2}$ Tetrahydrosäure enthält.

Um einen Einblick in die Constitution dieser Tetrahydrosäure zu erhalten, habe ich sie in alkalischer Lösung mit Kaliumpermanganat oxydirt. Leider schlugen die Versuche in dieser Richtung fehl, da die Säure hierbei grösstentheils in Benzoësäure verwandelt wird. Es gelang mir zwar, nachdem die Benzoësäure durch Kochen des alkalischen Rückstandes nach der Oxydation mit absolutem Alkohol entfernt worden, eine kleine Menge einer in Wasser und Aether leicht löslichen Säure zu erhalten, die bei etwa $100^{\circ}$ schmolz, doch konnte ich

16) Inaug. - Dissert. Würzburg 1892. S. 26. 
sie wegen der schlechten Ausbeute nicht reinigen. Ihr Silbersalz enthielt 61,67 pC. Silber, während glutarsaures Silber 62,46 pC. erfordert, demnach ist es zweifelhaft, ob Glutarsäure vorliegt, da ich aus der Substanz das charakteristische Zinksalz dieser Säure nicht erhalten konnte. Soviel habe ịch doch constatirt, dass bei der Oxydation weder Bernsteinsäure noch Malonsäure entsteht, weil das Calciumsalz der erhaltenen Säure in Wasser sehr leicht löslich ist. Spuren von Oxalsäure wurden in dem rohen Oxydationsproduct wahrgenommen, aber vor der Extraction mit Aether als Kalksalz entfernt.

Für die Structur der aus Benzoësäure durch Natriumamalgam erhaltenen Tetrahydrosäure konnte ich bis jetzt keine directen Beweise beibringen. Nach der Theorie sind folgende drei Tetrahydrobenzoësäuren möglich, nämlich

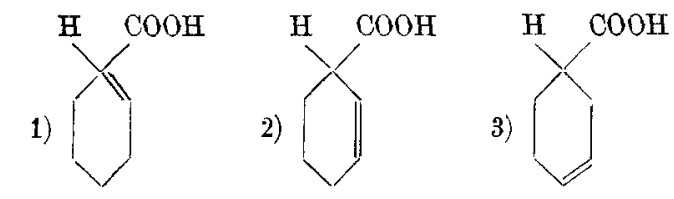

denen nach der Baeyer'schen Nomenclatur die Namen 1) $\Delta^{1}$, 2) $\boldsymbol{A}^{2}$ und 3) $\boldsymbol{A}^{3}$ Tetrahydrobenzoësäure zukommen. Da die $d^{1}$ Tetrahydrosäure, die, wic weiter unten mitgetheilt werden wird, auf einem anderen Wege erhalten worden ist, mit der Tetrahydrosäure aus Benzoësäure nicht identisch ist, kommt dieser entweder die Formel 2) oder 3) zu. Für die Annahme der Formel 2) sprechen nun folgende Thatsachen:

1. Dic Säure lässt sich durch Kochen mit starker Kalioder Natronlauge leicht in $A^{1}$ Tetrahydrosäure überführen. Nun hat $v$. B a eyer gezeigt, dass die ungesättigten Hydrosäuren sowohl der Terephtal- und Phtalsäurereihe, wie auch Säuren mit offener Kette, welche die doppelte Bindung in $\beta \gamma$-Stellung enthalten, durch eine analoge Behandlung leicht in die beständigeren $A^{1}$ Isomeren, welche die doppelte Bindung unmittelbar an dem Carboxyl haben, übergehen. Freilich ist 
nicht ausgeschlossen, dass auch eine $A^{3}$ Tetrahydrosäure beim Kochen mit fixen Alkalien sich in die $A^{1}$ Form umlagern könne.

2. Die Säure wird sowohl im freien Zustande, wie auch als Methylester ${ }^{17}$ ) schon durch den Luftsauerstoff zu Benzö̈säure oxydirt. Nach v. Baeyer's Erfahrungen sind die ungesättigten Säuren der Terephtalsäurereihe resp. deren Methylester, welche die doppelte Bindung $A^{2}$ enthalten, an der Luft am leichtesten veränderlich. So wird $\operatorname{der} \boldsymbol{A}^{2,5}$ Dihydroterephtalsäuremethylester, worin die $\mathcal{A}^{2}$ Bindung zweimal vorkommt, in wenigen Stunden im Wasserbade zu Terephtalsäureester oxydirt ${ }^{18}$ ); ebenso wird der Ester der $A^{1,5}$ Dihydroterephtalsäure schon bei gewöhnlicher Temperatur verharzt ${ }^{19}$ ). Weiter reduciren die genannten Säuren in freiem Zustande Silberlösung, die $\boldsymbol{A}^{2,5}$ Dihydrosäure schon ohne Zusatz von Ammoniak, die $A^{1,5}$ Säure in ammoniakalischer Lösung ${ }^{20}$ ); ähnlich verhält sich nun die $A^{2}$ Tetrahydrobenzoësäure, die ammoniakalische Silberlösung, obwohl schwierig, beim Kochen reducirt.

Nach v. Baeyer's letzter Publication ${ }^{21}$ ) sind die Verhältnisse in der Phtalsäurereihe verwickelter; doch kann erwähnt werden, dass das Anhydrid der $\boldsymbol{A}^{2,5}$ Dihydrophtalsäure beim Erhitzen im Wasserbade viel Phtalsäure liefert. Auch diese Säure enthält nämlich die doppelte $\boldsymbol{d} \beta \gamma$-Bindung zweimal; denn die doppelte Bindung $A^{2}$ befindet sich, wie aus ihrer Formel ersichtlich, in dieser Stellung zu Carboxyl (1) und in Bindung $A^{6}$ zum Carboxyl (2):<smiles>O=C(O)C1CCCCC1C(=O)O</smiles>

${ }^{77}$ Ber. d. deutsch. ehem. Ges. 24, 1865.

${ }^{18)}$ Diese Annalen 251, 267.

19) Diese Annalen 258, 19.

20) Diese Annalen 251, 267.

*) Diese Annalen $\mathbf{2 6 9}, 145$. 
Indessen ist zu bemerken, dass das Anhydrid der cis$\boldsymbol{A}^{3,5}$ Dihydrophtalsäure,<smiles>O=C(O)[C@H]1C=CC[C@H](C(=O)O)[C@H]1C(=O)O</smiles>

die in Bezug auf die Stellung der doppelten Bindungen zum nächstliegenden Carboxyl analog constituirt ist, diese Reaction nicht zeigt. In der eis - und trans $-\Delta^{3,5}$ Dihydrophtalsäure, wie auch in der $A^{2,4}$ Dihydrophtalsäure, welche die $A^{2}$ Bindung einmal enthält, äussert sich doch die leichte Oxydirbarkeit in ihrem Verhalten zu Silberlösung, welche reducirt wird; ebenso verhält sich $A^{2,6}$ Dihydrophtalsäure.

Schliesslich ist zu erwähnen, dass die $\boldsymbol{A}^{2,5}$ Dihydroterephtalsäure von Kaliumpermanganat zu Terephtalsäure $\left.{ }^{22}\right), A^{3,5}$ Dihydrophtalsäure zu Phtalsäure ${ }^{23}$ ) oxydirt wird, während $A^{2}$ Tetrahydrobenzoësäure Benzoësäure in grosser Menge liefert. Es existirt mit einem Worte eine gewisse Analogie zwisehen dieser Tetrahydrobenzoësäure und den Dihydrosäuren der Phtalsäurereihe, welche die doppelte Bindung $\boldsymbol{A}^{2}$ enthalten.

3. Die Säure liefert, mit Kaliumpermanganat oxydirt, weder Bernsteinsäure noch Malonsäure. Falls ihr die Structur $A^{\mathbf{3}}$ zukäme, musste sie, wenigstens theilweise, in die eine von diesen Säuren gespalten werden, wie die Betrachtung folgender Formeln lehrt:
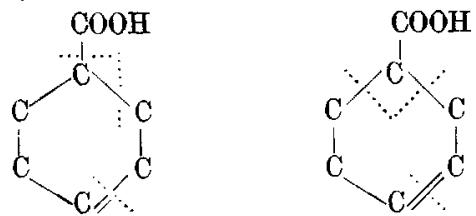

Aus den angefuhrten Gründen finde ich also die Structur $\mathrm{H} \mathrm{COOH}$

22) Diese Annalen 251, 267.

23) Diese Annalen 269', 195. 
für die betreffende Säure wahrscheinlicher und käme ihr sonach die schon angewandte Benennung $\boldsymbol{A}^{2}$ Tetrahydrobenzoësäure zu. Indess ist die obige Formel erst dann als festgestellt zu betrachten, wenn die noch fehlende $A^{3}$ Tetrahydrosäure dargestellt sein und sich von ilhr verschieden erweisen wird.

\section{Dibromid der $A^{2}$ Tetrahyārosäure.}

Die $d^{2}$ Tetrahydrosäure, in Chloroform aufgelöst, nimmt momentan Brom auf, wobei ein Dibromid entsteht. Da die rohe Säure etwas Aether und Wasser enthält, auch Nebenreactionen nicht ganz ausgeschlossen sind, so bleibt bei Anwendung von roher Säure die addirte Brommenge, sowie die Ausbeute etwas hinter der berechneten zurück und am besten wird in folgender Weise verfahren.

$25 \mathrm{~g}$ rohe Dibydrosäure werden in $150 \mathrm{ccm}$ trocknem Chloroform aufgelöst; in die mit Eis und Kochsalz stark abgekühlte Lösung lässt man das mit dem á fachen Volumen Chloroform verdünnte Brom eintropfen. Die Absorption geht sehr leicht von statten, weshalb der Sättigungsmoment leicht zu erkennen ist. Aus der Lösung, welche gegen Ende der Operation reichlich Krystalle absetzt, wird das Chloroform und Spuren von Brom in Vacuum verdunstet; der weisse Rückstand, welcher einen scharfen Geruch verbreitet, wird unter Erwärmen in wenig Benzol aufgelöst und Ligroïn in Ueberschuss zugesetzt. Auch kann die durch Durchsaugen von trockner Luft etwas eingeengte Chloroformlösung gleich mit dem 5 fachen Volumen Ligroïn versetzt werden. Im ersten Falle scheidet sich das Dibromid in etwa 12 Stunden in grossen Krystallen aus, im zweiten erhält man eine zweite, dichte Fällung, die sich beim Stehen noch vermehrt. Die Mutterlaugen scheiden beim freiwilligen Verdunsten weitere Krystalle $a b$, welche aber weniger rein sind, und schliesslich bleibt eine geringe Menge zuräck, aus der weiter nichts krystallisirt. Von diesem Oel bleibt um so mehr, je weniger sorgfältig bei der Bromirung gekühlt wurde. 
Die zuerst abgeschiedenen Krystalle schmelzen bei $163^{\circ}$, bei Umkrystallisiren aus wenig heissem Eisessig unter Zusatz von Wasser steigt der Schmelzpunkt auf $166^{\circ}$, welcher als der richtige Schmelzpunkt des Dibromides anzusehen ist. Für die Einheitlichkeit der $d^{2}$ Tetrahydrosäure war es wichtig festzustellen, ob noch ein anderes Dibromid bei der Reaction entsteht, ein solches musste in der zweiten Krystallisation, die niedrigeren Schmelzpunkt und andere Löslichkeitsverhältnisse zeigte, gesucht werden. Sie wurde in der Kälte in Soda aufgelöst, die etwas trübe Lösung mit Aether ausgeschüttelt und mit Schwefelsäure versetzt, wobei die Säure zuerst als ölige Trübung abgeschieden wird, die bald in Krystalle übergeht. Von diesen wurde ein Theil zweimal durch Auflösen in wenig heissem Eisessig und Versetzen der Lösung mit heissem Wasser bis zur Trübung umkrystallisirt, wobei schliesslich einheitliche Krystalle vom Schmelzpunkt $166^{\circ}$ erhalten wurden. Ihre Identität mit dem Dibromid der $d^{2}$ Tetrahydrosäure wurde übrigens auch durch die Bildung des für diese Verbindung charakteristischen Bromlactons vom Schmelzpunkt $67^{\circ}$ (siehe weiter unten) erwiesen. Den zurückgebliebenen Theil der ursprünglichen Krystalle nahm ich nunmehr in Soda auf; die Lösung wurde, um das $A^{2}$ Tetrahydrodibromid in Lacton überzuführen, gekocht, das Lacton mit Aether entfernt und die wässrige Lösung mit einigen Tropfen Kaliumpermanganatlösung versetzt, bis die Farbe stehen blieb. Nach dem Entfärben und Filtriren schied diese Lösung mit Schwefelsäure eine bromfreie Säure aus, die nach Umkrystallisiren aus heissem Wasser bei $122^{\circ}$ schmolz. Es lag Benzoësäure vor, was zum Ueberfluss durch einen Sublimationsversuch bestätigt wurde. Da bei Uebergang des Dibromides der $\Delta^{2}$ 'Tetrahydrosäure in Lacton keine Benzoësäure entsteht, und da ferner die zugesetzte Kaliumpermanganatlösung zur Erzeugung der erhaltenen Menge Benzoësäure durchaus ungenügend war, so muss die zweite Krystallportion ein Gemenge des als Hauptproduct gebildeten Dibromids mit Benzoësäure sein und 
entsteht demnach aus der rohen $\Delta^{2}$ Tetrahydrosäure nur ein Dibromid. Was den Ursprung der Benzoësäure betrifft, so muss, da ihre Fintstehung während der Bromirung ausgeschlossen ist, angenommen werden, dass sie in der angewandten Tetrahydrosäure enthalten war, was sowohl durch ungenügende Hydrirung, als auch durch später stattgefundene Oxydation durch die Luft erklärlich wird.

Das Dibromid der $\rfloor^{2}$ Tetrahydrobenzoësäure, Schmelzpunkt $166^{\circ}$, krystallisirt aus benzolhaltigem Ligroïn in grossen dicken Prismen; aus Eisessig, nach dem Ausfällen mit warmem Wasser, in grossen glasglänzenden Blättern, die quadratischer Habitus und deutliche Pyramidenflächen zeigen; aus Chloroform, wie aus absolutem Alkohol, die es leicht aufnehmen, krystallisirt es in platten, spitzigen Prismen.

$$
\begin{aligned}
& 0,2559 \mathrm{~g} \text { gaben } 0,3352 \mathrm{AgBr} \text {. } \\
& 0,3576 \mathrm{~g} \quad, \quad 0,3864 \mathrm{CO}_{2} \text { und } 0,1170 \mathrm{H}_{2} \mathrm{O} \text {. } \\
& \text { Berechnet für } \\
& \mathrm{C}_{7} \mathrm{H}_{10} \mathrm{Br}_{2} \mathrm{O}_{2} \\
& \text { (: } \quad 29,37 \quad 29,47 \\
& \mathrm{H} \quad 8,50 \quad 3,36 \\
& \mathrm{Br} \quad 55,94 \quad 555,73
\end{aligned}
$$

Das Dibromid kann bei Zimmerwärme in concentrirter Sodalösung ohne Zersetzung aufgelöst werden. Die Lösung setzt nach einigen Minuten das schwerlösliche Natronsalz in undeutlichen Blättern ab. Lässt man sie längere Zeit stehen, oder wird sie gekocht, so scheidet sich das weiter unten zu beschreibende Monobromlacton aus. Alkoholisches Kali spaltet Bromwasserstoff $\mathrm{ab}$, unter Bildung einer ungesättigten Aethersäure $\mathrm{C}_{9} \mathrm{H}_{14} \mathrm{O}_{3}$ (siehe weiter unten).

Ans dem Dibromid können die Bromatome durch Natriumamalgam leicht eliminirt werden, unter Rückbildung der $d^{2}$ Tetrahydrosäure. $\mathrm{Zu}$ dem Ende wird es in Soda aufgelöst und die Lösung, anfangs unter guter Kühlung, mit dem Amalgam versetzt. Nach 24 stündigem Stehen bei Zimmerwärme wird die Lösung verdünnt und die Säure mit Schwefelsäure und 
Aether isolirt. Sie ist jetzt reiner als die rohe Säure und namentlich von Benzoësäure frei. Dass dic ursprüngliche Säure hierbei wirklich regenerirt wird, wurde durch die Darstellung des Dibromides (F. p. $166^{\circ}$ ) and des Bromlactons (F. p. $67^{\circ}$ ) constatirt.

Monobromlacton der $\gamma$-Oxyhexahydrobenzoësäure.

Unter Zugrundelegung der $\Delta^{2}$ Formel für die Tetrahydrosäure kommt dieser wohldefinirten Verbindung die Structur zu:

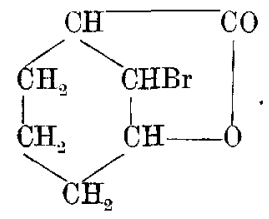

Thre Bildung ist für die Säure bezw. ihr Dibromid besonders charakteristisch. Wenn die Lösung des Dibromides in überschüssiger Soda- oder Potaschelösung erwärmt wird, so trübt sie sich milchig und es wird ein schweres, bromhaltiges Oel abgeschieden. Die Reaction verläuft quantitativ; ein Ueberschuss an Soda schadet nicht, wenn man nicht allzulange Zeit kocht. Wenn man mit reinem Dibromid arbeitet, wird das Oel nach dem Erkalten sofort fest, und zwar erstarrt es in ziemlich grossen rhomboëdrischen Krystallen. Aus der Mutterlauge scheidet sich beim Stehen noch eine weitere Menge kleinerer Krystalle aus, die entweder briefcouvertähnliche Zwillinge mit quadratischem Umriss oder platte Prismen bilden. $\mathrm{Zur}$ Reinigung wird das Lacton nach dem Trocknen entweder in sehr wenig Benzol gelöst und mit Ligroïn ausgefüllt, oder aber man benutzt Alkohol als Lösungsmittel und setzt Wasser bis zur eintretenden Trübung hinzı. In beiden Fällen werden lange, platte Prismen erhalten.

$$
\begin{aligned}
& 0,2157 \mathrm{~g} \text { gaben } 0,3231 \mathrm{CO}_{2} \text { und } 0,084 \mathrm{H}_{\mathrm{g}} \mathrm{O} . \\
& 0,1561 \mathrm{~g} " 0,1430 \mathrm{AgBr} \text {. } \\
& \text { Annalen der Clomie 271. Bd. }
\end{aligned}
$$




$\begin{array}{lcc} & \text { Berechnet für } & \text { Gefunden } \\ & \mathrm{C}_{\mathbf{7}} \mathrm{H}_{\mathbf{0}} \mathrm{BrO}_{2} & \\ \mathrm{C} & \mathbf{4 0 , 9 7} & 40,85 \\ \mathrm{H} & \mathbf{4 , 3 9} & \mathbf{4 , 3 3} \\ \mathrm{Br} & \mathbf{3 9 , 0 2} & \mathbf{3 8 , 9 8}\end{array}$

Der Schmelzpunkt des Lactons liegt bei $67^{\circ}$. Es ist in Benzol, Aether, Alkohol, Eisessig leicht, in Wasser schwer löslich. Mit Natronlauge erwärmt geht es nur schwierig in Lösung. Alkoholisches Kali spaltet schon in der Kälte Bromwasserstoff $a b$, unter Bildung eines in Wasser leicht löslichen, noch nicht näher untersuchten Körpers, welcher mit Kaliumpermanganat stark reagirt.

Was die Constitution des Lactons betrifft, so ist wegen seiner glatt verlaufenden Bildung anzunehmen, dass das in $\gamma$-Stellung befindliche Bromatom mit dem Carboxyl reagirt, wie aus der oben angeführten Structurformel hervorgeht. Der Körper ist also als das Lacton der $\beta$-Brom- $\gamma$-Oxyhexahydrobenzoësäure zu bezeichnen. Seine Bildung ist der Entstehung des Bromlactons aus dem Dibromid der stabilen Dihydro- $\beta$ Naphtoësäure ganz analog ${ }^{24}$ ):

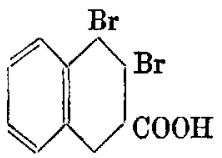

giebt

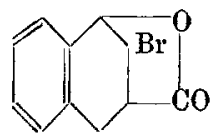

Die Leichtigkeit der Lactonbildung zeigt wieder in eclatanter Weise die Aehnlichkeit der hydroaromatischen Säuren mit den Fettsäuren.

Structur der Herrmann'schen Benzoleïnsäure.

Wie schon in dem Literaturnachweis hervorgehoben wurde, hat Herrmann vor etwa 30 Jahren ${ }^{25}$ ), durch Behandlung von Benzoësäure in saurer Lösung mit Natriumamalgam, eine Tetrahydrosäure dargestellt, die er Benzoleïnsäure nannte.

24) v. Baeyer. Diese Annalen 266, 191.

25) Diese Annalen 182, 75. 
Der leichte Uebergang dieser Säure, ihrer Salze und ihres Methylesters in Benzoësäure liess vermuthen, dass sie mit der in ähnlicher Weise, aber in alkalischer Lösung dargestellten $A^{2}$ Tetrahydrobenzoësäure identisch sei. Auch der lästige Geruch der freien Säure und ihres Methylesters war täuschend ähnlich, in dem Siedepunkt des letzteren, 188-189 (Quecksilber ganz im Dampf) stimmte die Benzoleïnsäure mit der $A^{2}$ Tetrahydrosäure überein. Um die Identität der beiden Säuren endgültig zu beweisen, habe ich die Benzoleïnsäure nach Herrmann's Vorschrift bereitet und ganz wie oben beschrieben in Dibromid verwandelt. Dieses schmolz bei $166^{\circ}$ und war dem Dibromid der Tetrahydrosăure in Krystallform und Löslichkeit durchaus ähnlich. Mit Soda gekocht ging es in ein Lacton tiber, das den Schmelzpunkt $67^{\circ}$ und die sonstigen Eigenschaften des Monobromlactons der $\gamma$-Oxyhexahydrobenzoësäure zeigte. Durch Auflösen in Alkohol und Ausfällen mit Wasser stieg sein Schmelzpunkt nicht weiter.

Es ist somit erwiesen, dass die sogen. Benzoleïnsăure von Herrmann mit der $\Delta^{2}$ Tetrahydrobenzoësäure identisch ist, und dass die Hydrirung der Benzoësäure sowohl in saurer wie in alkalischer Lösung denselben Verlauf nimmt.

\section{Einwirkung von alkoholischem Kali auf das Dibromid der $\Delta^{2}$ Tetrahydrosäure.}

Alkoholisches Kali nimmt schon bei Zimmerwärme die ganze Brommenge aus dem Dibromid heraus, und es entsteht eine bei $73^{\circ}$ schmelzende, bromfreie und woblcharakterisirte Säure, die ich früher ${ }^{26}$ ) als eine Dihydrosäure von der Structur<smiles>O=C(O)C1CCCCC1</smiles>

bezeichnet habe. Eine eingehende Untersuchung hat nunmehr ergeben, dass die Verbindung keine Dibydrosäure ist, son-

${ }^{26)}$ Ber. d. deutsch. chem. Ges. 24, 2622. 
dern die Formel $\mathrm{C}_{\mathbf{9}} \mathrm{H}_{\mathbf{1 4}} \mathrm{O}_{3}$ einer Aethoxytetrahydrobenzoësäure besitzt.

Zur Darstellung des Körpers wird das Dibromid der $\boldsymbol{A}^{2}$ Tetrahydrosäure $(20 \mathrm{~g})$ in wenig Alkohol aufgelöst und in gesättigte, absolut-alkoholische Kalilösung, welche etwas mehr ąls die berechnete Menge Kalihydrat (12 g) enthält, eingetragen, wobei das in Alkohol ziemlich schwer lösliche Kaliumsalz auskrystallisirt. Wenu man ohme Kühlung arbeitet, erwärmt sich die Lösung, und die Reaction vollzieht sich unter Abscheidung von Bromkalium in kurzer Zeit, was für die Reinheit des Productes nachtheilig ist, da in diesem Falle viel ölige Substanz gebildet wird. Deshalb kühlt man mit Eiswasser während des Eintragens des Dibromides gut ab und lässt das Gemisch einige Stunden in kaltem Wasser stehen, später ohne Kühlung bei Zimmertemperatur. Es scheidet sich allmählich Bromkalium ab, und in zwei Tagen ist die Reaction vollendet. Man erhitzt eine Stunde unter Rückfluss, stumpft das überschüssige Alkali bis zur schwach sauren Reaction mit Chlorwasserstoffsäure $a b$, sonst färbt sich die Lösung beim Abdampfen gelb, filtrirt von den unorganischen Salzen ab und verjagt den Alkohol im Wasserbade. Der kaum gelb gefärbte Rückstand wird in wenig Wasser aufgenommen und die Säure mit mässig concentrirter Salzsäure als bald erstarrendes Oel abgeschieden. Die harten Krystallmassen der rohen Säure krystallisirt man aus kochendem Wasser um (etwa $200 \mathrm{ccm}$ auf die angegebene Menge), unter welchem die Substanz vor dem Lösen schmilzt; die heiss gesättigte Lösung wird mit kaltem Wasser unter Umschütteln gekühlt; die hierbei sich abscheidende geringe Trübung, die von Spuren mitgelöster Harze herrührt, kam nach dem Erkalten abfiltrirt werden, da die Säure selbst leicht übersättigte Lösungen bildet. In kurzer Zeit fängt auch in der filtrirten Lösung die Abscheidung von Krystallen an, die sich während der folgenden 24 Stunden noch vermehren. Die Krystalle sind farblos und fast ganz rein (die Analyse III ist mit diesem Material ausgefubrt), doch habe ich sie 
gewöhnlich nochmals umkrystallisirt, wobei der Schmelzpunkt nicht weiter erhöht wird. Die Mutterlaugen enthalten noch viel Substanz aufgelöst, die nach dem Verdunsten über Schwefelsäure in grossen, wohlausgebildeten Krystallen anschiesst. Die letzten Reste der Lösung scheiden gewöhnlich ein $0 \mathrm{el}$ in geringen Mengen $a b$.

I. $0,1832 \mathrm{~g}$ mit chromsaurem Blei verbrannt gaben $0,4284 \mathrm{CO}_{2}$ und $0,1355 \mathrm{H}_{2} \mathrm{O}$.

II. $0,2106 \mathrm{~g}$ mit chromsaurem Blei verbrannt gaben $0,4897 \mathrm{CO}_{\mathrm{g}}$ und $0,1624 \mathrm{H}_{2} \mathrm{O}$.

III. $0,1843 \mathrm{~g}$ mit ehromsaurem Blei verbrannt gaben $0,4277 \mathrm{CO}_{2}$ und $0,1444 \mathrm{H}_{2} \mathrm{O}$.

\begin{tabular}{ccccc} 
& Berechnet für & \multicolumn{3}{c}{ Gefunden } \\
& $\mathrm{C}_{9} \mathrm{H}_{14} \mathrm{O}_{3}$ & I. & II. & III. \\
$\mathrm{C}$ & 63,53 & 63,79 & 63,29 & 63,29 \\
$\mathrm{H}$ & 8,23 & 8,22 & 8,57 & 8,72
\end{tabular}

Diese Analysen, sowie die für das Silbersalz und das Dibromid erhaltenen Zahlen stellen die Formel $\mathrm{C}_{9} \mathrm{H}_{14} \mathrm{O}_{3}$ ausser Zweifel.

Ich bezeichne die Säure aus später klarzulegenden Gründen als $\gamma$-Aethoxy- $A^{1}$-T'trahydrobenzoësäure. Sie bildet ziemlich lange, wasserhelle Prismen mit deutlichen Grundflächen und schmilat bei $73^{\circ}$. Schon unter $100^{\circ}$ giebt sie Dämpfe ab und scheint, auf einem Platinblech erhitzt, ohno Zersetzung flüchtig zn sein, wenigstens wird Kohle nicht abgeschieden; die Dämpfe verbrennen mit leuchtender Flamme. In den gewöhnlichen Solventien, Wasser ausgenommen, ist sie sehr leicht löslich; aus der alkoholischen Lösung wird die Säure durch Wasser ölig ausgefällt. In Natriumcarbonat gelöst wird sie durch Kaliumpermanganat momentan oxydirt, nach beendigter Oxydation konnte nichts Krystallinisches erhalten werden. Die Salze sind überhanut leicht löslich und wenig charakteristisch.

Das Silbersal: fällt durch Silbernitrat aus der concentrirten ammoniakalischen Lösung der Säure als käsiger, lichtbeständiger Niederschlag aus, der auch in kaltem Wasser lös- 
lich ist. Es schmilzt beim raschen Erhitzen zwischen 130$140^{\circ}$ zu einer gelben Flüssigkeit, welche bald dunkel wird.

$0,1425 \mathrm{~g}$ gaben $0,0552 \mathrm{Ag}$.

$0,2169 \mathrm{~g}, \quad 0,0841 \mathrm{Ag}$.

Berechnet für Gefunden

Ag $\quad 38,99$

$$
\mathrm{C}_{9} \mathrm{H}_{13} \mathrm{O}_{3} \cdot \mathrm{Ag}
$$

$$
38,74 \quad 38,77
$$

Gegen starke Kalilauge zeigt sich die Säure ganz beständig. Sie wurde in 30 procentiger Kalilange aufgelöst und die Lősung erhitzt, bis sie sich von ausfallendem Kalisalz trübte. Aus der Lösung wurde die Säure farblos wieder abgeschieden, und nach dem Umkrystallisiren aus Wasser zeigte sie den früheren Schmelzpunkt $73^{0}$.

Mein College, Dr. W. Ramsay, hatte die Güte, die Säure krystallographisch zu untersuchen, wofür ich ihm bestens danke. Er theilt Folgendes mit.

„Probe 2 (nach dem Kochen mit Kalilange erhalten): An den wahrscheinlich monosymmetrischen Krystallen konnte der Prismenwinkel $\propto \mathrm{P}=110^{\circ} 20^{\prime}$ bestimmt werden. Die Verticalzone enthält ausserdem ein Pinakoïd, das den Prismenwinkel symmetrisch halbirt $\left(55^{\circ} 10^{\circ}\right)$.

Probe 1 (ursprüngliche Säure). Die Krystalle sind zum Messen nicht geeignet, doch konnten annähernd gleiche Werthe der Winkel wie die obengenannten bestimmt werden."

Die Bromirung wurde in verschiedener Weise ausgefübrt. Die früher mit gutem Erfolg angewandte Methode, das Chlorid der Säure mit Brom zu versetzen, schlug hier ganz fehl. Beim nachherigen Kochen des Productes mit Ameisensäure wurde nur eine kleine Menge fester Substanz als eine bei $208^{\circ}$ schmelzende, in langen Nadeln krystallisirende, bromhaltige Säure erhalten, welche, aus ihrer grossen Beständigkeit beim Kochen mit fixen Alkalien und gegen Kaliumpermanganat zu schliessen, eher ein Benzol- als ein Hydrobenzolderivat darstellt; leider reichte die erhaltene Menge zu einer Analyse nicht aus. Ausserdem hatten sich nur dunkelgefärbte Schmieren 
gebildet. Auch als die in Eisessig aufgelöste Säure in zugeschmolzenen Röhren mit Brom (4 Atome auf 1 Mol. Säure) bei $120^{\circ}$ bis zur Entfärbung erhitzt wurde, entstand nur ein Gemenge gebromter Säuren, welches nicht zum Krystallisiren zu bringen war. Erst als ich die Einwirkung des Broms in Chloroformlösung vornahm, wurde ein festes, gut charakterisirtes Bromid erhalten.

Die Säure nimmt hierbei nur schwierig Brom auf, und es hat sich herausgestellt, dass nur ein Dibromid entsteht, gleichgültig ob die Saure mit 2 oder 4 Atomen Brom zusammengebracht wird. Die unten angeführte Analyse I ist mit einer Substanz angeführt, entstanden durch Zngabe einer 2 Molekülen entsprechenden Brommenge. Zur Darstellung des Dibromides wird die Chloroformlösung der Säure mit 1 Mol. Brom versetzt und das Gemenge etwa 16 Stunden an einem kühlen Ort unter Abschluss des Tageslichtes stehen gelassen. Zur Erzielung eines leicht zu reinigenden Productes ist die Anwendung von ganz trocknen Materialien unerlässlich, weil sonst leicht Bromwasserstoffabspaltung eintritt. Nach Verdunsten des Lösungsmittels im Vacuum wurde der gelbgefärbte Rückstand über Calciumoxyd gestellt, wobei er ziemlich vollständig zu grossen Prismen erstarrt, diese wurden mit etwas Ameisensaure (sp. Gew. 1,2) angerührt, nachher auf porösen Platten abgesaugt, um ölige Beimengungen zu entfernen, die weisse Krystallmasse in wenig warmem Benzol aufgelöst und mit niedrig siedendem Petroleumäther versetzt. Beim Stehen scheidet sich das Dibromid in grossen, plattenartig ausgezogenen Prismen ab. Statt dessen kann man es auch aus wenig warmer Ameisensäure umkrystallisiren, wobei dicke, spulenförmige Prismen gebildet werden.

I. 0,1144 g gaben $0,1305 \mathrm{AgBr}$.

II. $0,1649 \mathrm{~g}, \quad 0,1857 \mathrm{AgBr}$.

\begin{tabular}{cccc} 
& Berechnet für & \multicolumn{2}{c}{ Gefunden } \\
$\mathrm{Cr}$ & $\mathrm{C}_{8} \mathrm{H}_{14} \mathrm{Br}_{2} \mathrm{O}_{3}$ & $\overbrace{\mathrm{I} .}$ & II. \\
48,48 & 48,50 & 47,92
\end{tabular}


Das Dibromid schmilzt bei $125-126^{\circ}$; seine Lösung in Soda wird erst nach einer Stunde von einem Tropfen Kaliumpermanganatlösung entfärbt, woraus hervorgeht, dass es keine doppelte Bindung mehr enthält.

Das Natronsalz des Dibromids ist in Wasser sehr schwer löslich, und kann, da es sehr beständig ist, zur Reindarstellung der Säure angewandt werden. Wird die Säure mit gesättigter Sodalösung übergossen, so gesteht die Flüssigkeit bald zu einem Brei, aus den achteckigen Prismen des Natronsalzes bestehend. Beim Erwärmen löst sich dieses auf und krystallisirt nachher wieder aus. Beim Kochen der Lösung wird Brom nur spurenweise abgespalten; nachher entfürbt sie Kaliumpermanganat kanm nennenswerth und das Dibromid kann wieder als bald erstarrendes Oel abgeschieden werden. Diese Beständigkcit gegen Soda ist für die Constitutionsbestimmung der ursprünglichen Säure ron grosser Wichtigkeit, ebenso der Umstand, dass keine Spur eines Lactons gebildet wird.

Zur Darstellung des Hydrobromides wurde die Aethoxytetrahydrosäure mit einer bei $0^{0}$ gesättigten Lösung von Bromwasserstoff in Eisessig während 12 Stunden auf $100^{\circ}$ in zugeschmolzenen Röhren erhitzt, und das Product, nachdem die grösste Menge der Säuren mit Soda abgestumpft worden, mit Aether isolirț. Aus dem Anfangs flüssigen Rückstand schieden sich beim Stehen über Kalk glasglänzende Prismen aus, welche, von den öligen Beimengungen durch Abpressen befreit und aus Eisessig unter Zusatz von Wasser umkrystallisirt, den constanten Schmelzpunkt $166^{\circ}$ und die sonstigen Eigenschaften des Dibromides der $\boldsymbol{d}^{2}$ Tetrahydrosäure zeigten, namentlich beim Kochen mit Sodalösung in das durch den Schmelzpunkt $67^{\circ}$ wie seine Krystallform gekennzeichnete Bromlacton der $\gamma$-Oxyhexahydrobenzoësäure verwandelt wurde. Ein einfaches Hydrobromid war also nicht entstanden, falls ein solches nicht in dem unkrystallisirbaren Theil des Productes vorlag, was ich vorläufig unentschieden lasse, sondern der Bromwasserstoff hatte auch die Aethoxygruppe angegriffen. 
Die Entstehung der Aethoxysäure $\mathrm{C}_{9} \mathrm{H}_{14} \mathrm{O}_{3}$ verläuft wahrscheinlich in zwei Phasen; in der ersten bewirkt ein Molekül Kali Abspaltung von einem Molekül Bromwasserstoff:

$$
\mathrm{C}_{8} \mathrm{H}_{9} \mathrm{Br}_{2} \cdot \mathrm{COOH}+\mathrm{KHO}=\mathrm{C}_{6} \mathrm{H}_{8} \mathrm{Br} \cdot \mathrm{COOH}+\mathrm{KBr}+\mathrm{H}_{2} \mathrm{O} \text {, }
$$

wobei eine bromirte Tetrahydrobenzoësäure entsteht; auf diese wirkt nun das zweite Molekül als Aethylalkoholat ein:

$$
\mathrm{C}_{6} \mathrm{H}_{8} \mathrm{Br} \cdot \mathrm{COOH}+\mathrm{C}_{2} \mathrm{H}_{5} \mathrm{OK}=\mathrm{C}_{6} \mathrm{H}_{8}\left\{\begin{array}{l}
\int_{100 \mathrm{C}} \mathrm{C}_{8} \mathrm{H}_{5} \\
\mathrm{COOH}
\end{array}+\mathrm{KBr} .\right.
$$

Es ist anzunehmen, dass die beiden Reactionen parallel mit einander verlaufen. Die so gebildete Aethoxytetrahydrobenzoësäure ist ungesättigt und reagirt deshalb mit Kaliumpermanganat; sio enthält aber nur eine doppelte Bindung, da sie ein Dibromid bildet, dessen Verhalten gegen Kalínmpermanganat wieder deutlich zoigt, dass es völlig gesättigt ist. Das Verhalten der Aethoxytetrahydrosäurc gegen Bromwasserstoff hat nichts Bofremdendes, wenn man bedenkt, dass auch alkylirte Oxyfettsäuren beim Lrhitzen mit Halogenwasserstofisäuren das Alkyloxyl gegen Halogen austausehen könneu. Die Reaction vollzieht sich auch in diesem Falle in zwei parallel verlaufenden Phasen; zuerst wird Bromwasserstoff hinzuaddirt:

$$
\mathrm{C}_{6} \mathrm{H}_{8}\left\{\begin{array}{l}
\mathrm{OC}_{2} \mathrm{H}_{5} \\
\mathrm{COOH}
\end{array}+\mathrm{HBr}=\mathrm{C}_{6} \mathrm{H}_{9} \mathrm{Br}\left\{\begin{array}{l}
\mathrm{OC}_{2} \mathrm{H}_{5} \\
\mathrm{COOH}
\end{array},\right.\right.
$$

und darauf zersetzt das zweite Molekül die Aethoxygruppe:

$$
\mathrm{C}_{6} \mathrm{H}_{9} \mathrm{Br}\left\{\begin{array}{l}
\mathrm{OC}_{2} \mathrm{H}_{5} \\
\mathrm{COOH}
\end{array}+\mathrm{HBr}=\mathrm{C}_{6} \mathrm{H}_{9} \mathrm{Br}_{2} \mathrm{COOH}+\mathrm{C}_{2} \mathrm{H}_{5} \mathrm{OH} .\right.
$$

Für die Aethoxytetrahydrobenzoësäure sind, unter Zugrundelegung der früher dargelegten Constitution des Dibromides der $\mathcal{A}^{2}$ Tetrahydrosäure, zwei Formeln möglich:

1)<smiles>CCOC1CCCCC1</smiles>

2)

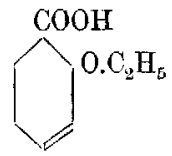

Nach Bildung und Verhalten des Dibronides dieser Säure ist die mit 1) bezeichnete Formel viel wahrscheinlicher. Erstens deutet schon die verhältnissmässig schwierige Aufnahme 
von Brom darauf hin, dass sich die doppelte Bindung in $\alpha \beta$-Stellung befindet, denn anch die später zu beschreibende $\boldsymbol{A}^{1}$ Tetrahydrosäure nimmt unter ähnlichen Verhältnissen nur langsam Brom auf, Sodann müsste das aus einer Säure der Formel 2) entstehende Dibromid beim Kochen mit Soda das $\gamma$-Bromatom nnter Bildung eines Bromlactons sehr leicht abgeben, während das Dibromid kein Lacton geben kann. Die Säure ist demnach wahrscheinlich als eine $\gamma$-Aethoxy- $\Delta^{1}$ Tetrahydrobenzoësäure zu betrachten.

Der directe Beweis für die Constitution könnte vielleicht mittelst des aus dem $\boldsymbol{A}^{2}$ Tetrahydrobenzoësäuredibromid entstehenden Lactons $\mathrm{C}_{7} \mathrm{H}_{9} \mathrm{BrO}_{2}$ geführt werden. Es ist nämlich nicht unmöglich, dass dieses beim Stehen mit alkoholischem Kali die Aethoxy- $\Delta^{1}$ Tetrahydrobenzoësäure liefern würde:

$$
\mathrm{C}_{8} \mathrm{H}_{8} \mathrm{Br} . \mathrm{COO}+\mathrm{C}_{2} \mathrm{H}_{5} \mathrm{OK}=\mathrm{C}_{6} \mathrm{H}_{8}\left\{\begin{array}{l}
\mathrm{OC}_{2} \mathrm{~B}_{5} \\
\mathrm{COOH}^{2}+\mathrm{KBr}
\end{array}\right.
$$

Bis jetzt ist diese Reaction nicht näher untersucht worden.

Hydrobromid der $A^{2}$ T'etrahydrobenzoësäure.

Obwohl das Product, das durch Addition von Bromwasserstoff an die $\Delta^{2}$ Tetrahydrosäure entsteht, ein Gemenge von Hydrobromiden darstellt, aus dem ich bis jetzt einen reinen Körper nicht abscheiden konnte, mögen die Bedingungen für seine Bildung kurz erwähnt werden, da es ein wichtiges Material ist für die Darstellung der Hexahydrobenzoësäure.

$\mathcal{A}^{2}$ Tetrahydrobenzoësäure wird mit dem 6 -fachen Volumen bei $0^{0}$ gesättigter, wässriger Bromwasserstoffsäure in zugeschmolzenen Gefässen während 12 Stunden in der Wasserbadkanone erhitzt. Das Product, ein dunkles Oel, wird sammt der Bromwasserstoffsäure in Eiswasser gegossen, die Lösung mit Soda fast neutralisirt und mit $\Lambda$ ether ausgeschüttelt. Die nach dem Abtreiben des Aethers zurückbleibende, butterähnliche Masse kann ohne Weiteres für die Darstellung der Hexahydrobenzoësäure dienen. 
Da das rohe Hydrobromid die später zu beschreibende, aus $\boldsymbol{\phi}^{\mathbf{1}}$ Tetrahydrosäure erhaltene $\beta$-Bromhexahydrobenzoësäure enthalten konnte, versuchte ich diesen Körper aus dem Gemenge zu isoliren, um so mehr, als dessen Entstehen den directen Beweis für die Structur der als $\Delta^{2}$ Tetrahydrosäure bezeichneten Säure geliefert haben würde. Wenn nämlich ein und dieselbe $\beta$-Bromhexahydrobenzoësäure durch Addition von Bromwasserstoff an $A^{1}$ und $A^{2}$ Tetrahydrosäure entstehen kann, so muss, da die Structur der ersteren sicher festgestellt ist, die letztere die doppelte Bindung in $\beta \gamma$-Stellung enthalten:

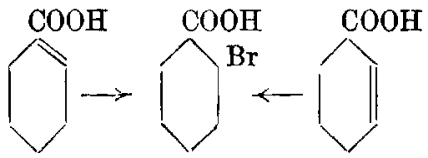

$\mathrm{Zu}$ dem Ende wurde einmal das aus $10 \mathrm{~g} A^{2}$ Tetrahydrosäure erhaltene rohe Dibromid einer Reinigung unterworfen, und zu dem Ende in verdünnter Sodalösung aufgelöst, wobei ein scharf riechendes, die Augen stark angreifendes Oel ungelöst bleibt, die Lösung schnell ausgeäthert und mit Schwefelsäure versetzt. Die abgeschiedene Säure wurde von Neuem mit Aether isolirt und der Rückstand nach längerem Stehen in der Winterkälte auf poröse Platten gestrichen. Das nunmehr ziemlich feste Product wurde später zweimal aus Ameisensäure umkrystallisirt; die kleine somit erhaltene Menge zeigte dabei in der That die Krystallformen der $\beta$-Brombexahydrobenzoësäure. Der Schmelzpunkt lag indess etwas hŏher, bei 112-1130, und das Product war offenbar mit Benzoësäure, welche aus der rohen Tetrahydrosäure stammte, verunreinigt, denn auch die Brombestimmung fiel $\mathrm{zu}$ niedrig aus. Statt der erforderlichen Brommenge von $38,65 \mathrm{pC}$. wurden nur $26,28 \mathrm{pC}$. erhalten. Wie alle anderen Versuche, die Constitution der $\boldsymbol{A}^{2}$ Tetrahydrosäure direct $z u$ bestimmen, schlug auch dieser fehl. 
Hexahydrobenzoësäure, $\mathrm{C}_{6} \mathrm{H}_{11} \mathrm{COOH}$.

Die Darstellung dieser Säure geschieht am besten in folgender Weise: Das rohe Hydrobromid der $\boldsymbol{A}^{2}$ Tetrahydrobenzoësäure wird in möglichst wenig ganz concentrirter Sodalösung gelöst, die Lösung mit Aether ausgeschüttelt und Natriumamalgam portionenweise eingetragen. Beim Schütteln verflüssigt sich das Amalgam schnell fast olne Gasentwicklung. Nach jedem Zusatz muss gut mit Eiswasser gekühlt werden; auch nachdem die Finwirkung träger geworden, fährt man noch einige Zeit fort zu kühlen; falls die dickliche Flüssigkeit schäunt, giesst man Aether darauf. Schliesslich wird bei Zimmerwärme über Nacht stehen gelassen, wobei festes Salz sich abscheidet. Um das Product bromfrei zu erhalten, setzt man Wasser zu, trennt die Flüssigkeit von dem Amalgam, säuert mit Schwefelsäure an und nimmt die abgeschiedene Säure mit Aether auf. Nach dem V'erdunsten des Aethers wird der Rückstand wieder in concentrirter Sodalösung aufgenommen und die Lösung $\%$ dem Amalgam zurückgegeben; schliesslich erwärmt man noch einige Stunden auf dem kochenden Wasserbade, verdiinnt mit Wasser und leitet Kohlendioxyd in die vom Quecksilber abgegossene Lösung bis zur Sättigung ein. Um die aus dem Hydrobromid zurückgebildete Tetrahydrosäure zu zerstören, fügt man Kaliumpermanganatlösung hinzu, bis die Farbe zwei Minuten stehen bleibt, filtrirt und isolirt die Säure.

Zur Reinigung stellt man, wenn mit kleineren Mengen gearbeitet wird, das Calciumsalz dar, und zwar löst man die Säure in Kalkwasser unter Umschütteln, wobei wenig Harz ungelöst bleibt; nachher wird die farblose Lösung auf ein kleineres Volumen eingeengt. Hierbei scheidet sich das schwerlösliche Calciumsalz der Hexahydrosäure als leichter Schaum auf der Flüssigkeit aus; es wird in der Kälte krystallinisch und kann durch Auflösen in Alkohol von 50 pC. und Versetzen der Lösung mit Wasser umkrystallisirt werden. Dic ursprüngliche Mutterlauge dampft man weiter ein, bis ein Salz erhalten wird, das 
mit Salzsäure eine krystallinische Säure abscheidet. Diese besteht grösstentheils aus Benzoësäure, die theils aus der verwendeten $\boldsymbol{A}^{2}$ Tetrahydrosäure stammt, theils durch die Oxydation nach beendigter Entbromung entstanden jst.

Eine ziemlich reine Hexahydrosäure, welche zum Beispiel 7.ur Darstellung von $\alpha$-Bromhexahydrobenzoësäure Verwendung fiuden kann, wird schon durch Destillation der rohen Säure gewonnen. Wenn man grössere Mengen chemisch reine Säure darstellen will, wird die Umwandlung in das Calciumsalz lästig; man reinigt sie dann besser durch Ueberführung in Ester, wodurch zugleich die Trennung von Benzoësäure erzielt wird. $Z u$ dem Ende wird $1 \mathrm{Th}$. Säure in $2 \frac{1}{2} \mathrm{Th}$. absoluten Alkohols gelöst, ein Drittel des Gesammtvolumens an concentrirter Schwefelsäure nach und nach ohne Abkühlung zugegeben und das Ganze über Nacht stehen gelassen. Durch Versetzen mit Wasser, Ausschütteln mit Aether und Behandlung der ätherischen Lősung mit Natronlauge wird die Benzoësäure, welche hierbei unesterificirt zurückbleibt, entfernt, während der Ester der Hexahydrosäure durch Rectification in reinem Zustande erhalten wird.

Die Hexahydrosäure entsteht auch beim 6-stündigen Erhitzen der $A^{2}$ Tetrahydrosäure mit der 10-fachen Menge concentrirter Jodwasserstoffsäure (Siedepunkt 128 $8^{\circ}$ ) auf $200^{\circ}$. Diese Methode eignet sich indess nicht zur Darstellung der Säure, weil ziemlich viel Benzoësäure gebildet wird und die Operation auch sonst unbequem ist. Dass hierbei Hexahydrobenzoësäure wirklich entsteht, wurde durch die Darstellung des Amides (Schmelzpunkt $181^{\circ}$ ) aus der vermittelst des Calciumsalzes gereinigten Säure nachgewiosen.

Un die Hexahydrosăure wasserfrei zu erhalten, was sonst schwierig gelingt, ist es nöthig, sie vor dem Destilliren mit Phosphorpentoxyd zu schütteln, aber nur kurze Zeit, weil sonst die gebildete Phosphorsäure zersetzend einwirkt. Die Verbrennung muss mit Bleichromat und sehr langsam ausgeführt werden, sonst wird sie immer unvollständig. 
$0,2104 \mathrm{~g}$ gaben $0,1749 \mathrm{H}_{\mathrm{g}} \mathrm{O}$ und $0,5050 \mathrm{CO}_{2}$.

$\begin{array}{ccr} & \text { Berechnet für } & \text { Gefunden } \\ & \mathrm{C}_{7} \mathrm{H}_{12} \mathrm{O}_{8} & \\ \mathrm{C} & \mathbf{6 5 , 6 3} & \mathbf{6 5 , 4 5} \\ \mathrm{H} & \mathbf{9 , 3 7} & \mathbf{9 , 2 4}\end{array}$

Die reine Säure krystallisirt selten gleich nach der Destillation, auch nicht beim Abkühlen auf $0^{\circ}$. Erst nachdem sie einige Stunden gestanden hat, wird sie auch bei Zimmertemperatur fest; sie erstarrt zu einer harten, blätterigen Krystallmasse, welche bei $28^{\circ}$ schmilzt. Sie ist in Wasser ziemlich wenig löslich, in Alkohol und Aether zerfliesslich. Ein Gehalt an Wasser scheint den Schmelzpunkt sehr zu erniedrigen. Der Siedepunkt liegt bei $232-233^{\circ}$ (Quecksilber ganz im Dampf). Die Säure besitzt einen unangenehmen und sehr anhaftenden Geruch. Sie reagirt mit Alkohol leicht unter Esterbildung; schon beim Kochen der Säure mit 10-20 procentigem Alkohol macht sich der Geruch des Esters bemerkbar.

Bekanntlich hat Baeyer bei Entwicklung seiner geistreichen Theorie der hydrirten Säuren der Phtalsäurereihe angenommen, dass die 6 Kohlenstoffatome des Hexamethylens in einer Ebene liegen. Diese Annahme setzt voraus ${ }^{27}$ ), dass die Hexahydrobenzoësäure nur in einer Modification existirt. Da die Entscheidung dieser Frage theoretisch interessant ist, habe ich die Hexahydrosäure in dieser Hinsicht eingehend untersucht; als Resultat kann ich jetzt, ohne auf die experimentellen Details einzugehen, anführen, dass ich die Säure nur in einer einzigen Form erhalten konnte. Die mit Jodwasserstoffsäure direct aus der Tetrahydrosäure dargestellte Substanz war in jeder Hinsicht mit der aus dem Hydrobromid erhaltenen identisch. Es gelang weder durch Erhitzen mit concentrirter Chlorwasserstoffsäure bis auf $240^{\circ}$, noch mit Wasser auf $260^{\circ}$ eine andere Modification $\mathrm{zu}$ erhalten, ebenso zeigte sich das Calciumsalz und das Amid aus der undestillirten Säure mit den entsprechenden

$\left.{ }^{27}\right)$ Diese Annalen $258,156$. 
Derivaten aus der destillirten, sowie aus der mit Jodwasserstoff dargestellten Säure identisch.

Das Calciumsalz, $\left(\mathrm{C}_{6} \mathrm{H}_{11} \mathrm{O}_{2}\right)_{2} \mathrm{Ca}+4 \mathrm{H}_{2} \mathrm{O}$, in der oben angegebenen Weise dargestellt, bildet lange Prismen, die häufig um einen gemeinsamen Mittelpunkt radial gruppirt sind. Das trockne Salz löst sich nur schwierig in heissem Wasser und wird beim Kochen damit theilweise dissociirt. Auch beim Eindampfen seincr Lösung tritt zuweilen saure Reaction ein; man thut deshalb gut, bei Abdampfen seiner Lösung vor dem Erkalten einige Tropfen Ammoniak zuzusetzen, wobei es sich gleich in Krystallen abscheidet. Es enthält 4 Mol. Wasser, welches bei $140^{\circ}$ entweicht.

I. $0,4001 \mathrm{~g}$ gaben $0,0798 \mathrm{H}_{2} \mathrm{O}$.

II. $0,3168 \mathrm{~g}$ (ans der mit Jodwasserstoff dargestellten Säure) gaben $0,0624 \mathrm{H}_{2} \mathrm{O}$.

\begin{tabular}{|c|c|c|}
\hline \multirow{2}{*}{ Berechnet } & \multicolumn{2}{|c|}{ Gefunden } \\
\hline & I. & II. \\
\hline 19,69 & 19,94 & 19,69 \\
\hline $\begin{array}{l}\text { Berechnet für } \\
\left(\mathrm{C}_{7} \mathrm{H}_{11} \mathrm{O}_{2}\right)_{5} \mathrm{Ca}\end{array}$ & \multicolumn{2}{|c|}{ Gefunden } \\
\hline 13,60 & \multicolumn{2}{|c|}{13,08} \\
\hline
\end{tabular}

Das Silbersale, $\mathrm{C}_{6} \mathrm{H}_{11} \mathrm{COOAg}$, scheidet sich beim Versetzen der Lösung des Calciumsalzes mit Silbernitratlösung, die eine Spur Ammoniak enthält, als weisser, käsiger Niederschlag aus. Es ist etwas in kochendem Wasser löslich und wird beim Erkalten in mikrokrystallinischen Flocken abgeschieden. Beim Erhitzen schmilzt es vor der Zersetzung zu einer schwarzen Flüssigkeit.

$0,282 \mathrm{~g}$ gaben $0,3652 \mathrm{CO}_{2}$ und $0,1261 \mathrm{H}_{8} \mathrm{O}$.

$0,1808 \mathrm{~g}$ gaben $0,0830 \mathrm{Ag}$.

$0,2142 \mathrm{~g} \quad$ 0,0984 Ag.

Berechnet für

Gefunden

$$
\mathrm{C}_{7} \mathrm{H}_{11} \mathrm{O}_{2} \mathrm{Ag}
$$

$\begin{array}{lrrrc}\text { C } & 35,74 & 35,32 & - & - \\ \text { H } & 4,64 & 4,97 & - & - \\ \mathrm{Ag} & 45,96 & - & 45,88 & 45,94\end{array}$


Der Methylester, durch Behandeln der methylalkoholischen Lösung der Säure mit Chlorwasserstoffgas oder concentrirter Schwefelsäure dargestellt, siedet bei $179-180^{\circ}$ (Quecksilber ganz im Dampf). Sein specifisches Gewicht beträgt $d_{0}^{0}=1,0138$; $\mathrm{d}_{20}^{20}=0,9946$.

Aethylester, $\mathrm{C}_{6} \mathrm{H}_{11} \mathrm{COOC}_{2} \mathrm{H}_{5}$. Dieses Derivat wird leicht in ähnlicher Weise wie der Methylester erhalten. Es stellt ein leichtfluissiges Oel dar, welches einen intensiven und anhaftenden Geruch nach Fettsäureestern besitzt. Der Siedepunkt liegt bei $194,5-195,5^{\circ}$ (Quecksilber ganz im Dampf). Das specifische Gewicht ist $\mathrm{d}_{4}^{4}=0,97230 ; \mathrm{d}_{20}^{20}=0,9597 ; \mathrm{d}_{4}^{20}=$ 0,93624 .

$0,2413 \mathrm{~g}$ gaben $0,6105 \mathrm{~g} \mathrm{CO}_{\mathrm{g}}$ und $0,2200 \mathrm{H}_{2} \mathrm{O}$.

$\begin{array}{ccc} & \text { Berechnet für } & \text { Gefunden } \\ & \mathrm{C}_{9} \mathrm{H}_{16} \mathrm{O}_{2} & \\ \mathrm{C} & 69,23 & 69,00 \\ \mathrm{H} & 10,26 & 10,13\end{array}$

Das Amid, $\mathrm{C}_{6} \mathrm{H}_{11} \mathrm{CONH}_{2}$, wurde in folgender Weise dargestellt. $2,5 \mathrm{~g}$ der Hexahydrosäure werden unter Kühlung mit $4 \mathrm{~g}$ Phosphorpentachlorid gemischt und. das Product vorsichtig in sehr concentrirtes, mit Eis und Kochsalz gekühltes Ammoniak eingetröpfelt. Hierbei scheidet sich der grösste Theil des Amides fest aus, während ein Bruchtheil in der Lösung verbleibt und mit Aether aufgenommen werden kann. Durch Umkrystallisiren aus heissem Wasser, worin es ziemlich löslich ist, kann es leicht gereinigt werden.

I. $0,1852 \mathrm{~g}$ gaben $19,6 \mathrm{cem}$ Stickgas bei $22^{\circ}$ und $716,0 \mathrm{~mm}$ Druck. II. $0,1497 \mathrm{~g} \quad, \quad 15,6 \mathrm{cem} \quad, \quad, 22^{\circ} \quad, \quad 719,0 \mathrm{~mm} \quad$,
Berechnet für $\mathrm{C}_{7} \mathrm{H}_{13} \mathrm{NO}$
$\mathrm{N}$
11,03 Gefunden

$\overbrace{11,27}^{\text {I. }}$ II $_{11,15}$

Das Amid bildet grosse, platte Prismen, welche Fettglanz zeigen und bei $184^{\circ}$ schmelzen. Alkohol und Aether nehmen es sehr leicht auf. Zum Vergleich wurde die aus $\boldsymbol{A}^{2}$ Tetra- 
hydrosäure beim Erhitzen mit concentrirter Jodwasserstoffsäure entstehende Hydrosäure in das Amid verwandelt; es zeigte denselben Schmelzpunkt $184^{\circ}$. Die Analyse II ist mit diesem Material ausgeführt.

\section{$\alpha$-Bromhexahydrobenzoësäure.}

Um diese Verbindung darzustellen, liess ich die berechnete Menge Brom (1 Mol.) auf das Chlorid der Säure in Gegenwart von Phosphoroxychlorid einwirken, nach dem Verfahren, mittelst dessen Ba e y er ${ }^{28}$ ) die Hexahydroterephtalsäure bromirte.

Je $4-6 \mathrm{~g}$ Brom wurde in einem tarirten Glaskügelchen eingeschmolzen und nachher das Gewicht desselben bestimmt. Nachdem so die Menge des Broms festgestellt war, wurde die hierfür berechnete Menge der Säure in ein einseitig zugeschmolzenes Rohr eingeführt und durch Phospliorpentachlorid allmählich und unter Kühlung in das Chlorid verwandelt; die letzten Spuren des Phosphorchlorids bringt man durch gelindes Erwärmen zum Verschwinden. Schliesslich wird das Kügelchen mit Brom eingeführt und nach dem Zuschmelzen des Rohrs durch heftiges Umschütteln zertrümmert. Die Bromirung fängt schon bei gewöhnlicher Temperatur an, verläuft aber sehr langsam, so dass crhitzt werden muss. Im Wasserbade ist die Reaction nach 8-10 Stunden beendet, wenn man mit obigen Substanzmengen arbeitet; bei $150^{\circ}$ in drei Stunden, doch wird das Product bei dieser Temperatur schon dunkel gefärbt, am besten wendet man eine Temperatur von $125^{\circ}$ an und erhitzt während 5 Stunden, wobei die restirende Flüssigkeit, wenn reine Materialien angewaudt werden, fast farblos ist. Die Röhren werden vorsichtig geöffnet, der aus mehreren Röhren vereinigte Inhalt in Wasser gegossen und unter Kühlung so lange geschüttelt (5 Minuten genügen), bis das Phosphoroxychlorid zersetzt ist; das zurückbleibende bromirte Chlorid wird in Aether aufgenommen, die Lösung mit Calciumchlorid getrocknet und

28) Diese Annalen 145, 175. 
der Aether verdunstet. Da kaltes Wasser auf das Chlorid nicht einwirkt, kochendes die entstehende Säure selbst zersetzt, wurde das Chlorid, um es in die Säure za verwandeln, zwei Stunden lang mit dem 10 fachen Volumen Ameisensäure (spec. Gew. 1,2) im Wasserbade erwärmt, wobei Kohlenoxyd und Chlorwasserstoff entweichen und der Ueberschuss des Lösungsmittels verdunstet. Es bleibt ein schwach gelblich gefärbtes Oel zurück, das nach dem Uebergiessen mit kaltem Wasser zu einer harten Krystallmasse erstarrt. Diese wird, um die anhängende Ameisensäure zu entfernen, gepulvert und mit Wasser gewaschen; nach dem Trocknen ist der Körper für die meisten Zwecke genügend rein.

Die Reinigung der bromirten Säure zur Analyse hat mir anfangs viel Schwierigkeiten gemacht, weil die Säure in den Lösungsmitteln, ausser Wasser, äusserst löslich ist. Wasser löst zwar beim Kochen etwas auf, aber beim Erkalten scheidet sich die Säure ölig aus. Auch aus der Lösung in Eisessig oder Alkohol wird sie durch Wasser immer als nicht erstarrendes Oel gefällt. Es giebt nur ein Lösungsmittel, das zur Umkrystallisation der Säure geeignet ist, nämlich concentrirte Ameisensäure. Besonders schön erhält man die Verbindung beim Abkühlen und Stehenlassen der concentrirten Lösung in grossen, glasglänzenden, sechsseitigen Blättern. Später habe ich gefunden, dass Ameisensäure (spec. Gew. 1,2) auch für andere mono- und dibromirte Säuren dieser Reihe ein ausgezeichnetes Lösungsmittel ist.

$0,1997 \mathrm{~g}$ gaben $0,1810 \mathrm{AgBr}$.

Berechnet für $\mathrm{C}_{6} \mathrm{H}_{10} \mathrm{Br} . \mathrm{COOH}$

$\mathrm{Br}$ 38,65
Gefunden

$39, \overrightarrow{3} 7$

$\alpha$-Bromhexahydrobenzoësäure schmilzt bei $63^{\circ}$ und hat einen scharfen, an Jodoform crinnernden Geruch; obwohl eine gesättigte Verbindung, wird sie in Soda gelöst, verhältnissmässig leicht durch Kaliumpermanganat oxydirt. Beim Kochen mit Wasser spaltet sie Bromwasserstoff ab, unter Bildung einer ungesättigten Säure. In der Kälte kann die Säure ohne Zer- 
setzung in Sodalösung oder Ammoniak aufgelöst werden, beim Kochen wird unter Abspaltung von Bromwasserstoff ungesättigte ölige Säure gebildet, ebenso beim Kochen mit Barytwasser. Das Silbersalz, ein krystallinischer Niederschlag, wird rasch unter Abgabe von Bromsilber zersetzt.

Was die durch die Formel

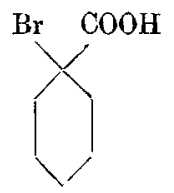

veranschanlichte Structur der Säure betrifft, so ist daran zu erinnem, dass das Bromatom, wie Baeyer nachgewiesen hat, beim Bromiren der Hexahydroterophtalsäure nach der beschricbenen Methode in die $\alpha$-Stellung eintritt. Diese Methode ist übrigens eine Modification der Hell-Volhard-Zelinsky'schen, welche nach Auwers ${ }^{29}$ ) immer $\alpha$-bromirte Säuren liefert.

\section{$A^{1}$ Tetrahydrobenzoësäure.}

Diese Säure kann entweder durch Einwirkung von alkoholischem Kali auf $\alpha$-Bromhexahydrobenzoësäure oder durch Einkochen der $A^{2}$ Tetrahydrosäurc mit wässrigen Alkalien erhalten werden. Sie wurde zuerst nach dem erstgenannten Verfahren dargestellt.

Alkoholisches Kali wirkt schon in der Kälte auf die $\alpha$ Bromhexahydrobenzoësäure ein. Hierbei kann nur eine Tetrahydrosäure von der Constitution $\boldsymbol{\Delta}^{1}$ entstehen:

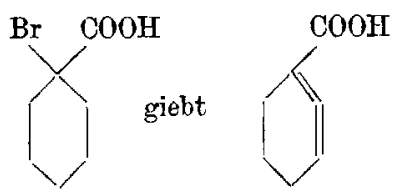

Die trockenc, rohe Monobromsäure wurde in wenig Alkohol gelôst und unter Abkühlung mit einer gesättigten Lösung von

$\left.{ }^{29}\right)$ Ber. d. deutsch. chem. Ges $\mathbf{2 4}, 2209$ und 2233. 
Kalihydrat (etwa 21/4 Mol.) in absolutem Alkohol versetzt. Aus der kalt gehaltenen Lösung schied sich bald Kaliumbromid aus, aber erst nach 3 Tagen war die Einwirkung zu Ende. Jetzt wurde einige. Stunden auf dem Wasserbade erhitzt, vom Kaliumbromid abfiltrirt und das Filtrat verdunstet. Der gelb gefärbte Rückstand wurde in Wasser gelöst und mit einem geringen Ueberschuss von Schwefelsäure versetzt, wobei die gebildete Säure als Oel ausfiel. Zur Reinigung wurde die Flüssigkeit mit Wasserdampf destillirt; die Säure ging ziemlich träge über, während harzige Beimengungen zurückblieben. Aus dem Destillate mit Aether aufgenommen, bildet sie ein ziemlich schwerflüssiges, beim Stehen theilweise erstarrendes Oel von charakteristischem, an ungesättigte Fettsäuren erinnerndern Geruch. Wird ihre Lösung in Chloroformlösung mit Brom versetzt, so tritt nicht sofort Entfärbung cin.

Die Eigenschaften der somit gebildeten $\boldsymbol{A}^{1}$ Tetrahydrobenzoësäure werden später näher angegeben. Vorläufig interessirte es mich, ihre Nichtidentität mit der $\boldsymbol{A}^{2}$ Tetrahydrosäure sicher festzustellen. $\mathbf{Z u}$ dem Ende wurde das Amid und das Dibromid in der unten beschriebenen Weise dargestellt. Jenes krystallisirt aus Wasser in grossen, fücherartig zusammengewachsenen, platten Prismen, die aus kleinen Octaëdern bestehen, aus Aether in grossen, undurchsichtigen Oetaëdern, die bei $127-128^{\circ}$ schmelzen. Das Dibromid bildet kleine Prismen mit deutlichen Endflächen und schmilzt bei $142^{\circ}$.

Bekanntlich hat v. Bacyer als eine allgemeine Regel festgestellt, dass die Hydroderivate der Phtal- und Terephtalsäure, welche die doppelte Bindung $\boldsymbol{A}^{2}$ enthalten, beim Einkochen mit Kali- oder Natronlange leicht cine Umlagerung erleiden, und zwar wandert die doppelte Bindung nach dem Carboxyl hin in die Stellung $\boldsymbol{d}^{1}$. Diese Regel hat sich auch bei der $\boldsymbol{A}^{2}$ Tetrahydrobenzoësäure bestätigt. Die Umwandlung erfolgt überaus leicht und glatt, indem eine fast quantitative Ausbeute erhalten wird. 
Man löst zu dem Ende $20 \mathrm{~g}$ rohe $\boldsymbol{A}^{\mathbf{2}}$ Tetrahydrosäure in einer Lösung von $30 \mathrm{~g}$ Kalihydrat in $90 \mathrm{~g}$ Wasser auf und erhitzt die Flüssigkeit in einem geräumigen Silbertiegel (in Glasgefässen tritt ein sehr lästiges Stossen auf) zum Kochen. Die Temperatur steigt allmählich auf $115-120^{\circ}$; nach etwa 20 Minuten trübt sich die Lösung unter Abscheidung eines festen Salzes, womit die Operation als beendigt angesehen werden kann. Nach dem Erkalten. wird der weisse Inhalt des Tiegels in Wasser gelöst und mit Schwefelsäure angesäucrt. Fs scheidet sich ein dickes Oel aus, welches mit Wasser aufgcnommen wird.

Zur Reinigung kann die Säure entweder mit Wasserdämpfen oder für sich destillirt werden, und zwar führt die letztere Behandlung leichter zum Zicle. Da die Verbindung von dem Luftsauerstoff nicht afficirt wird, führt man die Destillation in einem gewöhnlichen Fractionirkolben aus. Die Säure geht unter $760 \mathrm{~mm}$ Druck bei $240-243^{\circ}$ (Quecksilber ganz im Dampf) als dickflüssiges, farbloses Oel über.

Schon bei der Darstellung dieser Säure in kleinerem Maassstab aus $\alpha$-Bromhexahydrobenzoësäure ticl es mir auf, dass das undestillirte Product beim Ablühlen leicht erstarrte, dass aber die feste Säure keinen scharfen Schmelzpunkt zeigte ${ }^{30}$ ). Die jetzt in grösserer Menge durch Destillation gereinigte Säure fing schon an bei mässiger Zimmertemperatur zu erstarren, doch blieb auch hierbei ein Theil immer flüssig. Es scheiden sich zuerst briefcouvertähnliche Krystallindividuen aus, die nach längerem Stehen zu grossen, dicken Rhomboëdern auswachsen. Als sie nicht mehr an Grösse zunahmen, wurden sie von dem verhältnissmässig kleinen flüssigen Anthcil getrennt, auf poröse Platten gebracht und schliesslich zwischen Fliesspapier scharf abgepresst. Dic Analyse zeigte, dass die reine Verbindung vorlag.

$0,2376 \mathrm{~g}$ gaben $0,0,795 \mathrm{CO}$ und $0,1622 \mathrm{H}_{2} \mathrm{O}$.

so) Ber. d. deutsch, chem. Ges. 24, 2619. 


$\begin{array}{ccc} & \text { Berechnet für } & \text { Gefunden } \\ & \mathrm{C}_{7} \mathrm{H}_{10} \mathrm{O}_{2} & \\ \mathrm{C} & 66,67 & 66,52 \\ \mathrm{H} & 7,93 & 7,59\end{array}$

Da die Säure in einen flüssigen und einem festen Theil trennbar war, glaubte ich anfangs, dass zwei verschiedene Tetrahydrosäuren entstanden seien, und zwar könnte, da die Formel

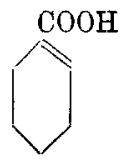

die geometrischen Isomeren nicht zulässt, die flüssige Verbindung entweder unveränderte $\boldsymbol{A}^{2}$ Säure oder aber die dritte isomere $\boldsymbol{A}^{3}$ Tetrahydrobenzoësäure vorstellen. Ihr Verhalten gegen Brom in Chloroformlösung, wobei momentane Entfärbung nicht eintrat, zeigte, dass keine dieser Annahmen zutrifft. Zur Entscheidung der Frage wurde die Bromirung in der unten beschriebenen Weise, unter intermediärer Darstellung des Säurechlorides, vorgenommen, und das gebildete bromirte Chlorid mit Ameisensäure zersetzt. Das so erhaltene Dibromid schmolz bei $142^{0}$, und zeigte sich auch in allen sonstigen Eigenschaften mit dem Dibromid der $A^{1}$ Tetrahydrobenzoësäure in jeder Beziehung identisch. Aus den Mutterlaugen konnte auch kein anderes Dibromid erhalten werden. Somit besteht auch der flüssige Theil aus $\boldsymbol{A}^{1}$ Tetrahydrosäure; das Flüssigbleiben wird also wohl durch geringe Verunreinigungen, vielleicht einen kleinen Wassergehalt veranlasst. Auch in der Leitfühigkeit, deren Bestimmung ich der Güte des Herrn U. Collan verdanke, zeigt der flüssige Theil der Săure keinen wesentlichen Unterschied von der festen; die Bestimmung wurde einmal direct mit der destillirten Säure, die also noch den flüssigen Theil enthielt, und zweitens mit der reinen krystallisirten Säure ausgeführt. 
$\Delta^{1}$ Tetrahydrobenzoësäure (flüssig).

\begin{tabular}{|c|c|c|c|}
\hline \multicolumn{4}{|c|}{$\mu_{\infty}=35.5$} \\
\hline$v$ & $\mu$ & $100 \mathrm{~m}$ & $100 x$ \\
\hline 32 & 9,16 & 2,58 & 0,00214 \\
\hline 64 & 12,88 & 3,63 & 0,00214 \\
\hline 128 & 17,76 & 5,30 & 0,00206 \\
\hline 256 & 24,07 & 6,78 & 0,00193 \\
\hline 512 & 31,73 & 8,94 & 0,00171 \\
\hline 1024 & 40,72 & 11,47 & 0,00145 \\
\hline \multicolumn{4}{|c|}{$K=0,00214$} \\
\hline \multirow[b]{2}{*}{$v$} & \multicolumn{2}{|c|}{$\begin{array}{c}\text { Tetrahydrobenzoësäure } \\
\mu_{\infty}=355\end{array}$} & \\
\hline & $\mu$ & $100 \mathrm{~m}$ & $100 x$ \\
\hline 32 & 9,35 & 2,63 & 0,00222 \\
\hline 64 & 13,17 & $3, \pi 1$ & 0,00223 \\
\hline 128 & 18,25 & 5,14 & 0,00218 \\
\hline 256 & 25,10 & 7,07 & 0,00210 \\
\hline 512 & 33,88 & 9,54 & 0,00171 \\
\hline 1024 & 45,03 & 12,69 & 0,00181 \\
\hline
\end{tabular}

Für die $\boldsymbol{A}^{2}$ Tetrahydrobenzoësäure ist nach früheren Bestimmungen die Constante $\mathrm{K}=0,00305$. Wie die Dihydronaphtoësäuren ${ }^{31}$ ) zeigen also auch die entsprechenden Derivate der Benzoësäure, dass die Leitfähigkeit, im Gegensatz zu den Beobachtungen Ostwald's in der Fettreihe, mit der Entfernung der doppelten Bindung von Carboxyl zunimmt.

In Cebereinstimmung mit der Leitfähigkeitsbestimmung giebt die destillirte Säure, aus welcher der feste Antheil noch nicht abgeschieden war, das Amid vom Schmelzpunkt 127 bis $128^{\circ}$ und das Dibromid der $A^{2}$ Tetrahydrosäure, welches bei $142^{\circ}$ schmilzt.

$\mathrm{Zu}$ den Eigenschaften der $\boldsymbol{A}^{1}$ Tetrahydrosäure ist noch Folgendes hinzuzufügen. Die Säure schmilzt bei $29^{\circ}$, und bei $20^{\circ}$ lösen $100 \mathrm{~g}$ Wasser $0,7 \mathrm{~g}$ der Säure. Das specifische Gewicht beträgt $\mathrm{d}_{20}^{20}=1,1089$. Sie ist gegen den Luftsauer-

51) Vgl. Baeyer, diese Annalen $\mathbf{2 6 6}, 176$. 
stoff ganz beständig, wird aber, in Soda aufgelöst, von Kaliumpermanganat momentan oxydirt, wobei keine Benzoësäure entsteht. Wie andere in $\alpha \beta$-Stellung ungesättigte Säuren addirt sie nur schwierig freies Brom. Der Geruch gleicht dem der $A^{2}$ Tetrahydrobenzoësäure, ist aber weniger unangenehm und anhaftend.

Die Salze sind überhaupt beständiger und schwerer löslich, wie die der isomeren $\Delta^{2}$ Tetrahydrosäure, ebenso sind sie leichter im krystallinischen Zustande zu erhalten.

Das Silbersalz fällt als undeutlich krystallinische, weisse und lichtbeständige Masse aus, wenn die ammoniakalische Lösung der Säure mit Silbernitrat versetzt wird. Mischt man die Lösungen heiss zusammen, so wird es beim Erkalten in platten Prismen, die rosettenförmig zusammengewachsen sind, erbalten.

$0,2850 \mathrm{~g}$ gaben $0,1320 \mathrm{Ag}$.

$\begin{array}{ccc} & \text { Borechnet für } & \text { Gefunden } \\ & \mathrm{C}_{7} \mathrm{H}_{9} \mathrm{O}_{2} \mathrm{Ag} & \\ \mathrm{Ag} & 46,36 & 46,32\end{array}$

Das Calciumsalz wird in farblosen, platten Prismen, die häufig um einen gemeinsamen Mittelpunkt angeordnet sind, erhalten, wenn warme Lösungen des Ammoniumsalzes und Calciumchlorid gemischt werden. Es ist in Wasser und Alkohol schwerer löslich als das entsprechende Salz der $A^{2}$ Säure und auch weniger dissociirbar; es enthält 1 Mol, Krystallwasser.

$0,2181 \mathrm{~g}$ verloren bei $140^{\circ} 0,0124 \mathrm{~g}$ und gaben $0,0704 \mathrm{CaCO}_{\mathrm{s}}$.

$\begin{array}{lcr} & \text { Berechnet für } & \text { Gefunden } \\ \mathrm{H}_{2} \mathrm{O} & \left(\mathrm{C}_{7} \mathrm{H}_{9} \mathrm{O}_{2}\right)_{2} \mathrm{Ca}+\mathrm{H}_{2} \mathrm{O} & \\ \mathrm{Ca} & 5,84 & 5,69 \\ \mathrm{Ca} & 12,99 & 12,89\end{array}$

Auch ein Ammoniumsalz ist ungewöhnlicher Weise im krystallisirten Zustande in glänzenden Blättern erhältlich, wenn die Säure in sehr concentrirter Ammoniakflüssigkeit aufgelöst wird. Die Hydrophtalsäuren geben keine Ammonsalze; beim Ver- 
dunsten ihrer ammoniakalischen Lösungen bleibt die Säure schliesslich in freiem Zustande zurück.

Eine concentrirte Lösung des Ammoniumsalzes reagirt mit schiedenen Metallsalzen in folgender Weise:

Bleinitrat, krystallinische weisse Fällung;

Magnesiumsulfat, keine Fällung:

Baryumacetat, krystallinischer weisser Niederschlag;

Cadmiumsulfat, voluminöser, weisser Niederschlag aus heissem Wasser in achteckigen, rosettenförmigen Blättern krystallisirend.

Nickelnitrat, flockiger, schmutzig gelber, fast farbloser Niederschlag;

Manganochlorid, schleimiger, bald krystallinisch werdender, schwach gelbrother Niederschlag;

Mercuronitrat, schwere krystallinische, weisse Fällung;

Zinksulfat, voluminöser, weisser Niederschlag, der bald krystallinisch wird;

Stannochlorid, schleimige, weisse Trübung;

Kupfersulfat, flockige, rein grüne Fällung, die beim Erwärmen schleimig und nach dem Erkalten krystallinisch wird.

Der Methylester, $\mathrm{C}_{6} \mathrm{H}_{9} \mathrm{COOCH}_{3}$, entsteht beim Versetzen der Lösung der $\boldsymbol{A}^{1}$ Tetrahydrosäure (1 Th.) in absolutem Methylalkohol $\left(21_{2}\right.$ Th. $)$ mit concentrirter Schwefelsäure. In gewöhnlicher Weise isolirt stellt der Ester eine farblose, lichtbrechende Flüssigkeit dar, welche bei $193,5-194,5^{\circ}$ (Quecks. i. D.) siedet; spec. Gew. $\mathrm{d}_{4}^{4}=1,05607, \mathrm{~d}_{20}^{20}=1,04364, \mathrm{~d}_{\underline{4}}^{20}=$ 1,04183 .

$0,3491 \mathrm{~g}$ gaben $0,8798 \mathrm{CO}_{\mathrm{q}}$ und $0,2622 \mathrm{H}_{2} \mathrm{O}$.

Berechnet für

$$
\mathrm{C}_{8} \mathrm{H}_{12} \mathrm{O}_{2}
$$

C 68,58

$\mathrm{H} \quad 8,58$
Gefunden

68,73

8,35

Das Amid, $\mathrm{C}_{6} \mathrm{H}_{9} \mathrm{CONH}_{2}$, wurde in ähnlicher Weise dargestellt, wie das entsprechende Derivat der $A^{2}$ Tetrahydro- 
säure. Die Säure wurde mit Phosphorpentachlorid zusammengebracht und die entstandene Mischung von Phosphoroxychlorid und Säurechlorid in sehr concentrirtes Ammoniak unter Abkühlung eingetröpfelt. Der entstandene feste Körper wurde in heissem Wasser aufgelöst, die kochende Lösung von harzigen Producten abfiltrirt und erkalten lassen. Nach dem Umkrystallisiren, wozu 15-20 procentiger Alkohol am besten geeignet ist, erhält man das Amid in schönen, mehrere Centimeter langen Prismen; diese bestehen aus Einzelkrystallen, die in einer Richtung ausgezogen und häufig fächerartig um ein gemeinsames Centrum angeordnet sind. Aus Aether krystallisirten Octaëder. Schmelzpunkt 127-128 . An dieser Stelle sei auf die merkwürdige Uebereinstimmung, welche gewisse physikalische Constanten der $\Delta^{1}$ Tetrahydrosäure und ihrer Derivate mit denen der Benzoësäure aufweisen, aufmerksam gemacht. So haben die Amide der beiden Säuren denselben Schmelzpunkt, und die Siedepunkte der freien Säuren sowie ihrer Methylester sind fast übereinstimmend.

I. $0,2047 \mathrm{~g}$ gaben $21,8 \mathrm{~cm}$ Stickstoff bei $22^{\circ}$ und $715 \mathrm{~mm}$ Druck.

II. $0,2009 \mathrm{~g} \quad, 21,0 \mathrm{ccm} \quad, \quad, 20^{\circ}, 715, "$, Berechnet für $\mathrm{C}_{7} \mathrm{H}_{11} \mathrm{NO}$ $\mathrm{N} \quad 11,20$ Gefunden

$\overbrace{11,33}^{\text {I. }}$ II. $_{11,23}$

Die Analyse I ist aus einem Material, welches aus der von $\boldsymbol{\alpha}$-Bromhexahydrobenzoësäure dargestellten Tetrahydrosäure dargestellt war, II aus der durch Umlagerung mittelst Alkali erhaltenen Sänre.

\section{$\beta$-Bromhexahydrobenzoësäure.}

Aus der $A^{1}$ Tetrahydrobenzoësäure können theoretisch zwei Hydrobromide entstehen, wie folgende Formeln zeigen:

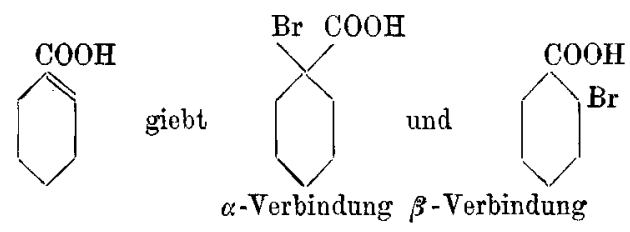


Das erste Hydrobromid ist die aus der Hexahydrosäure durch Substitution erbaltene $\alpha$-Bromsäure. Das zweite entsteht bei der Behandlung dor Tetrahydrosäure mit concentrirter Bromwasserstoffsäure.

Die Addition erfolgt leicht bei der Anwendung sowohl von wässriger, bei $0^{0}$ gesättigter Bromwasserstofisäure, wie von concentrirtem Bromwasserstoff-Eisessig, und zwar eignet sich die Eisessiglösung hierzu besser, weil das gebildete Product leichter erstarrt und reiner ist. Es wurden je $5 \mathrm{~g}$ der Säure mit $30 \mathrm{ccm}$ des Bromwasserstoff-Eisessigs während $4-5$ Stunden auf $100^{\circ} \mathrm{er}-$ hitzt. Man verdünnt nachher den Inhalt der Röhren mit Wasser, stumpft die Säuren grösstentheils mit Soda $a b$, filtrirt das zuerst ölig abgeschiedene, aber allmählich erstarrende Hydrobromid ab und befreit es auf Thontellern von Wasser. Die noch etwas weiche Krystallmasse krystallisirt man zweimal aus Ameisensäure (spec. Gew. 1,2), worin die bromirte Säure in der Kälte fast unlöslich ist, um. Die Analyse ergab:

0,1 ว $08 \mathrm{~g}$ gaben 0,1376 AgBr.

$\begin{array}{cc}\text { Berechnet für } & \text { Gefunden } \\ \mathrm{C}_{6} \mathrm{~B}_{11} \mathrm{BrCOOH} & \\ 38,65 & 38,83\end{array}$

Die $\beta$-Bromhexahydrobenzoësäure bildet grosse, platte Prismen oder Blätter, die anscheinend rhombisch sind, Domaflächen zeigen und Glasglanz besitzen. Der Schmelzpunkt liegt bei $108-109^{\circ}$, also bedeutend höher als bei der isomeren $\alpha$-Bromsäure. Wie diese Säure zeigt die betreffende Verbindung, obwohl gesättigt, eine deutliche Oxydirbarkeit durch Kaliumpermanganat, die wohl auf ihre Leichtzersetzlichkeit in alkalischer Lösung zurückzuführen ist.

Die Constitution ist ohne weiteres durch ihre Bildung festgestellt. Da sie das Bromatom in $\operatorname{der} \beta$-Stellung enthält, wurde versucht, durch Kochen ihres Natronsalzes mit Wasser Kohlensäure und Bromwasserstoff abzuspalten, um möglicherweise zu dem Tetrahydrobenzol zu gelangen; bekanntlich reagiren einige $\beta$-Lactone in dieser Weise. 
$\mathrm{Zu}$ dem Ende wurden $5 \mathrm{~g} \beta$-Bromhexahydrosäure in der berechneten Menge verdünnter Sodalösung gelöst und die Lösung gekocht. Sie trübte sich hierbei milchig und es destillirten einige Tropfen eines leicht flüchtigen, neutralen Oeles, das nach den niedrig siedenden Petroleumkohlenwasserstoffen roch; indessen war an die Isolirung des Körpers wegen der geringen Menge nicht zu denken. Das im Kolben zurückgebliebene Oel, das zu Boden sank und ziemlich schwer mit den Wasserdämpfen überging, erwies sich als eine Säure. Sie wurde in Soda aufgelöst und nach Auschütteln der Lösung mit Aether wieder abgeschieden. Es zeigte sich bei der Untersuchung, dass $A^{1}$ Tetrahydrobenzoësäure zurückgebildet worden war, denn die Säure lieferte, als sie wie $A^{1}$ Tetrahydrosäure bromirt wurde, das Dibromid der letztgenannten vom Schmelzpunkt $142^{\circ}$.

Demnach verhält sich die $\beta$-Bromhexahydrobenzoësäure, beim Kochen ihres Natronsalzes mit Wasser, so wie die in $\beta$-Stellung bromirten Fettsäuren; zum kleineren Theil scheint indess auch ein Kohlenwasserstoff zu entstehen.

Es wurde weiter das Verhalten der $\beta$-Bromhexahydrosäure zu alkoholischem Kali studirt. Wenn nämlich die Bromwasserstoffabspaltung in der Weise geschehen würde, wie die Formel

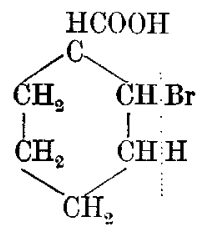

zeigt, so musste die $\boldsymbol{A}^{2}$ Tetrahydrobenzoësäure entstehen. Bei gewöhulicher Temperatur verlief die Einwirkung äusserst träge, beim Kochen wurde indessen neben Kaliumbromid ein in perlmutterglänzenden Blättern krystallisirendes Kaliumsalz gebildet, das abfiltrirt, in Wasser gelöst und mit Schwefelsäure zersetzt wurde. Es schied sich eine feste Säure aus, die gegen Kaliumpermanganat beständig war und nach Umkrystallisiren den Schmelzpunkt und die Eigenschaften der Benzoësäure zeigte. 
Ob nun dieses Ergebniss in der Art zu deuten ist, dass die somit gebildete Benzoësäure direct entsteht, oder dass sie, wie beim Kochen des Methylesters der $\boldsymbol{A}^{2}$ Tetrahydrosäure mit alkoholischem Kali, ihre Entstehung intermediär gebildeter $\boldsymbol{A}^{2}$ Tetrahydrobenzoësäure verdankt, lasse ich unentschieden. Es gelang wenigstens nicht, die Entstehung dieser Säure zu constatiren, und somit scheiterte auch dieser Versuch, ihre Constitution festzustellen.

\section{Dibromid der Al T'etrahydrobenzoësäure.}

Wenn man die $\Delta^{1}$ Tetrahydrosäure in Chloroform auflöst und die berechnete Menge Brom hinzufügt, so zeigt zwar eine geringe Selbsterwärmung, dass eine Reaction eintritt, aber erst nach $2-3$ stïndigem Stehen ist die Farbe des Broms grösstentheils verschwunden; nach dem Verdunsten bleibt ein dickflüssiges, gelbes Oel zurück, das im Exsiccator über Natronkalk nur theilweise erstarrt, weil sich ein Theil der Säure der Reaction entzogen hat; das Product entfärbt nämlich, in Soda gelöst, Kaliumpermanganatlösung noch ziemlich stark.

Nach der Theorie sind zwei geometrisch isomere Dibromide der $\Delta^{1}$ Tetrahydrobenzoësäure möglich, weil das $\alpha$-Kohlenstoffatom nach der Aufnahme von Brom asymmetrisch wird. Es wurden auch bei der directen Bromirung zwei verschiedene Dibromide gebildet, denn das erhaltene Product zeigt unter dem Mikroskope zweierlei Krystalle, nämlich gut ausgebildete Prismen und grosse, sechsseitige Blätter, von denen jene die schwerer lösliche, diese die leicht lösliche Modification darstellen, wie mich einige diesbezügliche Versuche gelehrt haben.

Leichter und vollständiger gelingt die Bromirung, wenn die Säure erst in Chlorid übergeführt wird. $\mathrm{Zu}$ dem Zweck wurde die $\Delta^{1}$ Tetrabydrobenzoësäure portionenweise mit kleinen Mengen Phosphorpentachlorid versetzt, bis keine Reaction mehr merkbar war, die letzten Spuren desselben durch gelindes Erhitzen in Lösung gebracht und die berechnete Menge Brom zu der entstandenen Mischung von Säurechlorid und Phosphoroxy- 
chlorid zugesetzt. Nach etwa 10 Minuten wird das Product in kaltes Wasser gegossen und unter Kühlung damit geschüttelt, bis das Phosphorchlorid zersetzt ist. Man nimmt das rückständige bromirte Säurechlorid, welches cinen scharfen, an Chlorphenole erinnnernden Geruch verbreitet, in Aether auf, trocknet die ätherische Lösung mit Calciumchlorid und verdampft das Lösungsmittel im Wasserbade. Das rückständige Oel wird wie beschrieben mittelst Ameisensäure in Hydrat verwandelt. Die Zersetzung erfolgt nur langsam; erst nach 8- bis 10 stündigem Erhitzen ist sie gewöhnlich zu Ende. Man erkennt diesen Punkt daran, dass eine Probe der Flüssigkeit, auf ein Uhrglas gebracht, beim Reiben mit dem Glasstabe sogleich Krystalle abscheidet; bei ungenügendem Erhitzen scheiden sich nur Oeltröpfchen, die entweder ganz flüssig bleiben oder nur schwierig erstarren, aus. Aus der etwas braun gefärbten, heiss filtrirten Lösung krystallisirt binnen einigen Stunden die weitaus grösste Menge des Dibromides in weissen, aus kleinen Prismen bestehenden Krystallaggregaten ans. Aus der Mutterlauge kann noch eine weitere Portion nach Verdampfen auf dem Wasserbad erhalten werden. Die Ausbeute ist fast quantitativ. Eigenthümlicher Weise bildet sich bei dieser Art der Bromirung nur die eine, schwerer lösliche Modification des Dibromides. Nur einmal habe ich aus den allerletzten Mutterlaugen eine kleine Menge eines Körpers in grossen Blättern, welche starken Glasglanz zeigten, gefunden, doch konnte ich ihn von dem beigemengten schwer löslichen Dibromid nicht trennen und somit nicht rein erhalten.

Das rohe Dibromid der $\boldsymbol{A}^{1}$ Tetrahydrosäure kann entweder durch Auflösen in Benzol und Ausfällen mit Ligroïn umkrystallisirt werden, oder man nimmt es in wenig warmem Eisessig auf und versetzt die Lösung mit Wasser in Ueberschuss. In dem ersten Falle wird es in grossen, compacten Prismen oder dicken Blättern, welche etwas grau gefärbt sind, im zweiten als kleine, weisse Prismen mit deutlicher Endenabstumpfung erhalten. 
I. $0,2583 \mathrm{~g}$ gaben $0,3409 \mathrm{AgBr}$.

II. $0,3058 \mathrm{~g}, 0,4020 \mathrm{AgBr}$.

Berechnot für
$\mathrm{C}_{7} \mathrm{H}_{10} \mathrm{Br}_{2} \mathrm{O}_{2}$$\overbrace{\substack{\mathrm{I} . \\ 56,15}}^{\text {Gefunden }}$

Das Material für die Analyse I stammt von einer $\Delta^{\mathfrak{1}}$ Tetrahydrosäure, die aus $\alpha$-Bromhexahydrobenzoësäure dargestellt war, für die Analyse II von einer durch Umlagerung mittelst Alkali erhaltenen.

Das Dibromid der $A^{1}$ Tetrahydrosäure schmilzt bei $142^{0}$ und kann, obwohl schwierig, sublimirt werden. Die Alkalisalze sind sowohl in Wasser wie in Alkohol schwer löslich. Das Dibromid ist ohne Zersetzung in kalter Sodalösung auflöslich; die Lösung ist gegen Kaliumpermanganat besonders beständig.

Beim Auflösen des Dibromides in alkoholischem Kali scheidet sich zuerst das schwerlösliche Kaliumsalz aus, welches bei gewöhnlicher Temperatur nur langsam und unvollständig von dem überschussigen Kali angegriffen wird. Erst nach längerem Kochen mit $3 \mathrm{Mol}$. in Alkohol aufgelöstem Kalihydrat wird alles Brom als Kaliumbromid abgeschieden. Hierbei entsteht eine ölige Säure, welche ich zuerst als die ursprüngliche Tetrahydrosäure ansah. Ein mit grösseren Mengen ausgefuhrter Versuch hat indessen gelehrt, dass die gebildete Säure viel leichter in Wasser löslich ist, als die $\Delta^{1}$ Tetrabydrosäure, und auch weniger beständig ist, so dass ich jetzt eher glaube, dass eine Dihydrosäure vorliegt. Bis jetzt ist es mir jedoch noch nicht gelungen, sie $\mathrm{zu}$ fassen und in reinem Zustande $\mathrm{zu}$ erhalten; denn als sie mit Aether isolirt und zum Erstarren im Exsiceator hingestellt wurde, verharzte sie und büsste in 12 Sunden ihre Löslichkeit in Wasser fast vollständig ein. Sie bildete nachher ein ziemlich festes Harz, worin unter dem Mikroskope einige Krystalle, wohlausgebildete Rhomboëder, sichtbar waren, dieselben liessen sich aber nicht isoliren. Wasser nahm aus der Substanz nur Spuren auf, in Alkohol war sie leichter löslich; die Lösung liess, mit Wasser versetzt, nur klebrige Flocken fallen. 
Falls die leicht lösliche Säure wirklich eine Dihydrosäure darstellt, so kommt ihr, gemäss ihrer Bildung, die Constitution

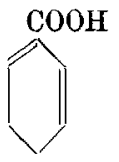

zu. Ihr Verhalten wäre ganz in Uebereinstimmung mit dem der $\boldsymbol{A}^{1,5}$ Dihydroterephtalsäure, deren Methylester nach $\mathrm{Herb}{ }^{32}$ ) binnen wenigen Stunden an der Luft verharzt, sowie dem der $\Delta^{2,6}$ Dihydrophtalsäure, deren Anhydrid beim Erwärmen, wie y. Baeyer gezeigt hat ${ }^{33}$ ), einer ähnlichen Umwandlung unterliegt. Diese beiden Säuren enthalten nämlich die doppelten Bindungen in derselben Stellung zu einem Carboxyl, wie nach der oben angeführten Formel die $\mathbf{A}^{2,6}$ Dihydrobenzoësäure:
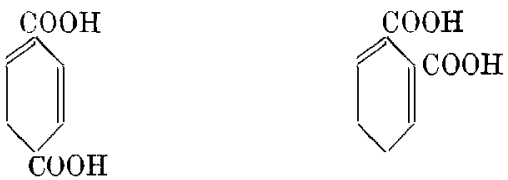

$\Delta 1,5$ Dihydroterephtalsäure

$d^{23,6}$ Dihydrophtalsäure.

Einwirkung von Sodalösung auf das Dibromid der $A^{1}$ Tetrahydrobenzoësäure.

Wenn das Dibromid mit überschüssiger Sodalösung gekocht wird, so entsteht eine ölige Säure, wahrscheinlich die ursprüngliche $\boldsymbol{A}^{1}$ Tetrahydrosäure. Anders verläuft die Reaction, wenn man den Körper in einer verdünnten Lösung, welche genau $1 / 2$ Molekül Natrinmearbonat enthält, auflöst und nachher kocht. Es scheidet sich eine kleine Quantität eines neutralen Oeles aus (wahrscheinlich findet hier eine ähnliche Reaction statt, wie beim Kochen des Natriumsalzes der $\beta$-Bromhexahydrobenzoësäure), aber zugleich geht der grösste Theil des Dibromides

32) Diese Annalen 258, 19.

$\left.{ }^{33}\right)$ Diese Annalen 269, 197. 
in eine in Wasser leicht lösliche Säure über, die mittelst des Calciumsalzes abgeschieden werden kann. Um diese $\mathbf{z u}$ isoliren, verfährt man in folgender Weise.

Man erwärmt die Lösung im kochenden Wasserbade, bis die Entwicklung von Kohlendioxyd nachlässt, entzieht ihr, nachdem die kalte Lösung mit Natriumhydroxyd neutralisirt worden, die neutralen Producte mit Aether und versetzt sie mit Calciumchlorid. Falls die Lösung verdünnt war, scheidet sich in der Kälte nichts aus, sondern man muss sie im Wasserbade verdunsten; jedenfalls begünstigt die Erwärmung das Auskrystallisiren des Calciumsalzes. Es bildet grosse, wasserhelle Tafeln, welche in kaltem Wasser fast unlöslich und, einmal abgeschieden, auch in kochendem wenig löslich sind.

Um die freie Säure $z u$ isoliren, wurde das Calciumsalz mit verdünnter Salzsäure versetzt; da eine Probe auch nach dem Verdunsten bis zur Syrupdicke nichts Krystallinisches abschied, wurde die Lösung mit Aether ausgeschüttelt, wobei die Säure nur schwierig in Lösung geht. Der ölige Rückstand gestand erst nach längerem Verweilen im Exciccator zur undeutlichen Krystallmasse. Da die Säure ausserdem hygroskopisch ist, liess die kleine, vorläufig zugängliche Menge eine weitere Reinigung nicht $\mathrm{zu}$. Der Umstand, dass sie ammoniakalische Silberlösung beim Kochen stark reducirte, sowie das ganze Verhalten liess eine Oxysäure vermuthen, was durch die folgenden, mit dem Calciumsalz vorgenommenen Bestimmungen bestätigt wird:

$0,2822 \mathrm{~g}$ Substanz verloren bei $120^{\circ} 0,0253 \mathrm{~g}$.

Berechnet für

Gefunden

$$
\left(\mathrm{C}_{6} \mathrm{H}_{9}(\mathrm{OH})_{2}, \mathrm{COO}\right)_{2} \mathrm{Ca}+2 \mathrm{H}_{2} \mathrm{O}
$$

Krystallwssser

$$
9,14
$$

$0,2579 \mathrm{~g}$, bei $120^{\circ}$ getrocknet, gaben $0,0733 \mathrm{CaCO}_{3}$.

$$
\begin{array}{ccc} 
& \text { Berechnet für } & \text { Gefunden } \\
\mathrm{Ca} & \left(\mathrm{C}_{6} \mathrm{H}_{9}(\mathrm{OH})_{2 .} \mathrm{COOO}\right)_{2} \mathrm{Ca} & \\
11,18 & 11,37
\end{array}
$$

Um die zwei in der Verbindung angenommenen Hydroxyle nachzuweisen, wurde versucht sie zu acetyliren, was auch gelingt, 
da das Diacetylderivat ein leicht erhältlicher und wohl charakterisirter Körper ist. $\mathrm{Zu}$ dem Fnde wurde das Calciumsalz mit überschüssigem Acetylchlorid übergossen und zur Einleitung der Reaction, die sonst ausbleibt, ein paar Tropfen Wasser zugesetzt. Die Reaction vollzieht sich in wenigen Minuten unter Selbsterwärmung und es entsteht eine fast klare Lösung. Nachher wird auf dem Wasserbade bis zur Syrupdicke eingedampft und nach dem Erkalten wenig Wasser zugesetzt. Nach einiger Zeit verwandelt sich der anfangs dickflusssige Rückstand in einen Brei kleiner, rhomboëdrischer Krystalle, welche abgesaugt und mit wenig Wasser nachgewaschen werden. Nach Umkrystallisiren aus heissem Wasser war die Verbindung rein, denn der Schmelzpunkt $72-73^{\circ}$ wird bei weiterem Krystallisiren nicht verändert. Analyse :

$0,1293 \mathrm{~g}$ gaben $0,2391 \mathrm{CO}_{\mathrm{g}}$ und $0,0756 \mathrm{H}_{\mathrm{g}} \mathrm{O}$.

\begin{tabular}{ccc}
\multicolumn{2}{c}{ Berechnet für } & Gefunden \\
$\left.\mathrm{C}_{6} \mathrm{H}_{9}(\mathrm{O} . \mathrm{COCH})_{3}\right)_{2} \cdot \mathrm{COOH}+\mathrm{H}_{2} \mathrm{O}$ & \\
$\mathrm{C}$ & $\tilde{5} 0,38$ & $\tilde{\mathbf{s} 0,43}$ \\
$\mathrm{H}$ & 6,87 & 6,50
\end{tabular}

Die erhaltenen Zahlen passen auf keine andere Verbindung, die sich von einem Dioxyderivat der Hexahydrobenzoësäure ableitet, weshalb man annehmen muss, das eine Diacetylverbindung einer Dioxysäure, welche $1 \mathrm{Mol}$. Krystallwasser enthält, vorliegt. Es konnte zwar nicht durch eine einfache Bestimmung constatirt werden, dass diese Wassermenge wirklich vorhanden war, weil der Körper schon unter $100^{\circ}$ flüssig wird und verdampft, indess zeigt sein eigenthümliches Verhalten beim Stehen über Schwefelsäure im Exsiccator, dass er Krystallwasser enthält. Die schön ausgebildeten Krystalle werden nämlich erst weich und klebrig und schliesslich fliessen sie zu einem formlosen Syrup zusammen. Dass hierbei wirklich Wasser, das zur Erhaltung der Krystalle nöthig ist, entweicht tnd nicht etwa eine Zersetzung oder Umlagerung stattfindet, geht daraus hervor, dass die zerflossene Masse, wenn man sie mit Wasser behandelt, wieder krystallisirt 
und dass die Krystalle denselben Schmelzpunkt und dieselben Formen zeigen wie früher.

Die Diacetyldioxyhexahydrobenzoësäure, der die folgende Zusammensetzung zukommt:

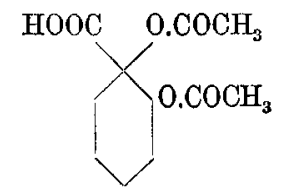

krystallisirt ausserordentlich schön in den beistehend abgebildeten Formen, deren Bestimmung ich der Güte des Herrn Dr. Wilh elm Ramsay verdanke. Er theilt darüber Folgendes mit:

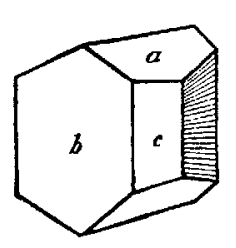

,Monosymmetrisch.

$\mathrm{a}: \mathrm{b}: \mathrm{c}=3,4176: 1: 1,1541$.

$\beta=86^{\circ} 51^{\prime}$.

Beobachtete Formen:

$$
\begin{aligned}
& \mathrm{b}=(100) \propto \mathrm{P} \infty \\
& \mathrm{a}=(011) \mathrm{P}_{\mathbf{x}} \\
& \mathrm{e}=(110) \propto \mathrm{P} .
\end{aligned}
$$

$$
\begin{aligned}
\text { Gemessen } & \text { Berechnet } \\
110: \overline{1} 10={ }^{*} 32^{0} 41^{\prime} & - \\
011: 0 \overline{1} 1={ }^{*} 98^{\circ} 7^{\prime} & - \\
110: 011={ }^{*} 42^{0} 40^{1} / 2^{\prime} & - \\
1 \overline{1} 0: 011=45^{0} 12^{\prime} & 44^{0} 35^{\prime} \\
100: 011=\left(85^{\circ} 30^{\prime}\right) & \left(87^{0} 56^{\prime}\right) \text { sehlecht ausgebildet. }
\end{aligned}
$$

Die Krystalle sind nach der c-Axe dick prismatisch. Sehr gute Spaltbarkeit parallel (100) 0.A.P. $\perp$ gegen 010. Schwache Doppelbrechung. Auf (110) weicht die Auslöschungsrichtung $14^{0}$ von der Verticalaxe ab."

Die Krystallisationsfühigkeit des Körpers ist überaus gross; so erhielt ich einmal, als etwa $0,1 \mathrm{~g}$ der Substan\% umkrystallisirt wurde und die Lösung bei gewöhnlicher Temperatur zum Trocknen verdunstete, die ganze Menge in zwei grossen Krystallen vereinigt, die allein in dem Gefäss zurückblieben. Er ist in Alkohol leicht löslich, von kaltem Wasser wird er schwieriger, von heissem Wasser leichter aufgenommen. Beim Auflösen in 
heissem Wasser schmilat er und löst sich nur allmählich; kochen darf man nicht, weil er dabei in Essigsäure and die freie Dioxysäure zerfällt. Auf Platinblech erhitzt scheint er unzersetzt zu verdampfen, wenigstens tritt keine Verkohlung ein; die Dämpe verbrennen mit leuchtender Flamme. Das Calciumsalz ist in Wasser sehr leicht löslich; das silbersalz, das auch in kaltem Wasser ziemlich löslich ist, krystallisirt in langen, feinen Nadeln und ist ziemlich lichtbeständig.

Ueber die Resultate einer schon begonnenen, vergleichenden Untersuchung über das Refractions- und Dispersionsvermögen der Ester der Hydrobenzoësäuren mit denen der Benzoësäureester werde ich demnächst berichten. Zugleich erwähne ich mit Dankbarkeit, dass Herr Professor v. Bae y er mir die dicsbezügliche Untersuchung der Phtalsäureester und der von ihm jüngst dargestellten Hydrobenzole gütigst überlassen hat.

IIelsing fors, im Juni 1892.

Geschlossen den 11. August 1892. 